University of New Hampshire

University of New Hampshire Scholars' Repository

2002

\title{
Multibeam volume acoustic backscatter imagery and reverberation measurements in the Northeastern Gulf of Mexico
}

Timoth C. Gallaudet

Scripps Institution of Oceanography

Christian de Moustier

University of California - San Diego

Follow this and additional works at: https://scholars.unh.edu/ccom

Part of the Oceanography and Atmospheric Sciences and Meteorology Commons

\section{Recommended Citation}

T. C. Gallaudet and C. P. de Moustier, 'Multibeam volume acoustic backscatter imagery and reverberation measurements in the northeastern gulf of Mexico', The Journal of the Acoustical Society of America, vol. 112, no. 2, p. 489, 2002.

This Journal Article is brought to you for free and open access by the Center for Coastal and Ocean Mapping at University of New Hampshire Scholars' Repository. It has been accepted for inclusion in Center for Coastal and Ocean Mapping by an authorized administrator of University of New Hampshire Scholars' Repository. For more information, please contact Scholarly.Communication@unh.edu. 


\title{
Multibeam volume acoustic backscatter imagery and reverberation measurements in the northeastern Gulf of Mexico ${ }^{\text {a) }}$
}

\author{
Timothy C. Gallaudet and Christian P. de Moustier \\ Marine Physical Laboratory, Scripps Institution of Oceanography, Mail Code 0205, \\ 8602 La Jolla Shores Drive, La Jolla, California 92037-0205
}

(Received 4 June 2001; revised 16 November 2001; accepted 4 February 2002)

\begin{abstract}
Multibeam volume acoustic backscatter imagery and reverberation measurements are derived from data collected in 200-m-deep waters in the northeastern Gulf of Mexico, with the Toroidal Volume Search Sonar (TVSS), a 68-kHz cylindrical sonar operated by the U.S. Navy's Coastal System Station. The TVSS's 360-degree vertical imaging plane allows simultaneous identification of multiple volume scattering sources and their discrimination from backscatter at the sea surface or the seafloor. This imaging capability is used to construct a three-dimensional representation of a pelagic fish school near the bottom. Scattering layers imaged in the mixed layer and upper thermocline are attributed to assemblages of epipelagic zooplankton. The fine scale patchiness of these scatterers is assessed with the two-dimensional variance spectra of vertical volume scattering strength images in the upper and middle water column. Mean volume reverberation levels exhibit a vertical directionality which is attributed to the volume scattering layers. Boundary echo sidelobe interference and reverberation is shown to be the major limitation in obtaining bioacoustic data with the TVSS. Because net tow and trawl samples were not collected with the acoustic data, the analysis presented is based upon comparison to previous biologic surveys in the northeastern Gulf of Mexico and reference to the bioacoustic literature. (C) 2002 Acoustical Society of America.
\end{abstract}

[DOI: $10.1121 / 1.1490597]$

PACS numbers: 43.30.Ft, 43.30.Sf, 43.30.Vh [DLB]

\section{INTRODUCTION}

Demographic pressures, overharvesting of marine fish stocks, and pollution are threatening marine ecosystems worldwide and provide incentives to focus fisheries management and plankton research efforts on conservation measures, thus requiring comprehensive knowledge of population dynamics and habitat variability. ${ }^{2}$ Such knowledge may be gained through ocean volume acoustic backscatter measurements that have been used to study populations of fish and plankton since the deep scattering layer was identified by Eyring et $_{\mathrm{al}}{ }^{3}$

Sonar echoes from volume scatterers are usually quantified using target strength (TS), which is the ratio of the intensity scattered by an object at a reference distance of $1 \mathrm{~m}$, to the incident intensity, and volume scattering strength $\left(S_{V}\right)$, which is the target strength of a unit volume. ${ }^{4}$ For volume scattering from $n_{V}$ scatterers per unit volume each with a mean differential scattering cross section $\left\langle\sigma_{\mathrm{bs}}\right\rangle, S_{V}$ and TS are related by

$$
\mathrm{TS}=10 \log _{10}\left\langle\sigma_{\mathrm{bs}}\right\rangle=S_{V}-10 \log _{10}\left(n_{V}\right) \quad(\mathrm{dB}) .
$$

Typically, measurements of $S_{V}$ with a high frequency sonar are used to estimate abundance and/or biomass by estimating

\footnotetext{
${ }^{a)}$ Portions of this paper were presented in talks at the Fourth Annual Symposium on Technology and the Mine Problem ${ }^{1}$, 13-16 March 2000, Monterey, CA, the First Oceanic Imaging Conference, 2000, 3-5 May 2000, in Newport, RI, and Acoustical Society of America Meetings in Seattle, WA, 20-26 June 1998, Berlin, Germany, 15-19 March 1999, and Newport Beach, CA, 3-8 December 2000.
}

$\left\langle\sigma_{\mathrm{bs}}\right\rangle$ from trawl or net tow samples with an appropriate scattering model, and using Eq. (1) to compute $n_{V}$. Such efforts are difficult because marine ecosystems contain multi-species, multi-size assemblages of organisms.

Another problem affecting these types of measurements is the spatial variability of zooplankton and fish, which may lead to large errors in abundance and biomass estimates obtained with single beam sonars. Single beam, vertically oriented echo-sounders have seen the most use in bioacoustic applications, ${ }^{5}$ but horizontally directed sonars have been used to characterize fish school structure, shape, and movement, ${ }^{6-9}$ as well as zooplankton distributions. ${ }^{10,11}$ Multibeam echo-sounders have been used in only a few bioacoustic studies to observe the swimming behavior of individual zooplankters, ${ }^{12}$ to demonstrate that vertical and lateral vessel avoidance by fish negatively bias abundance estimates derived from vertical echo-sounding sonars, ${ }^{13}$ and to provide more precise mapping and abundance of pelagic fish stocks in near-surface schools than can be obtained by vertical echo-sounding. ${ }^{14}$ The use of multibeam sonars in place of single-beam sonars for future bioacoustic surveys is warranted by their increased coverage, which can improve acoustic estimates of biomass and abundance and better characterize spatial distributions of organisms.

In this context, we present volume acoustic backscatter and reverberation measurements derived from data collected by the U.S. Navy's Toroidal Volume Search Sonar (TVSS), a $68-\mathrm{kHz}$ multibeam sonar capable of 360-degree imaging in a vertical plane perpendicular to its axis. We take advantage of 


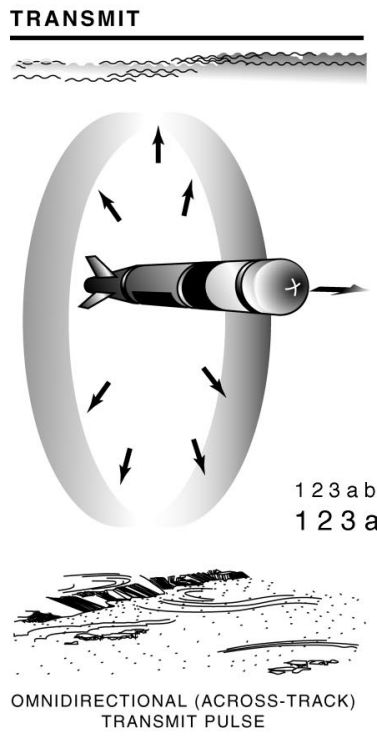

(a)

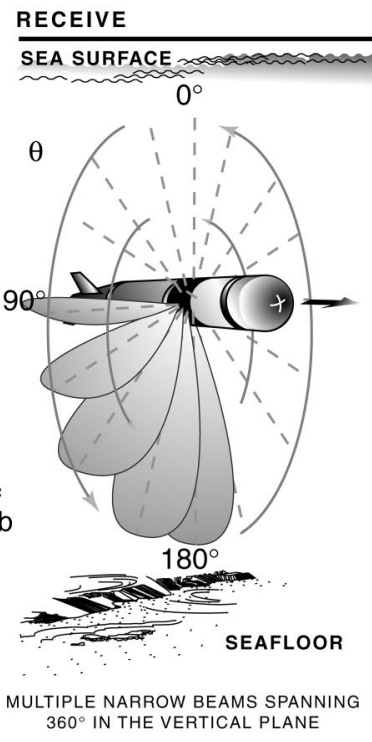

(b)

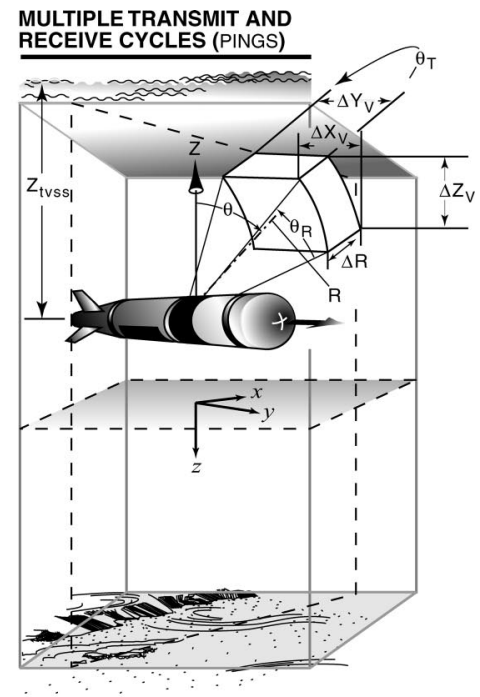

(c)

FIG. 1. The TVSS is designed for mine-hunting while deployed on an autonomous or unmanned underwater vehicle (AUV/UUV). In this study, a towed vehicle was used. (a) After transmission of a "toroidal" pulse, the sonar extracts the returned signal in directions spanning 360 degrees about the TVSS's axis (b). This geometry is used to construct undersea imagery for multiple horizontal and vertical planes using data collected over successive transmit-receive cycles (pings) (c). Only vertical imagery is presented in this study, where $x, y$, and $z$ correspond to across- and along-track directions relative to the towfish and depth relative to the sea surface. The resolution of the TVSS data is defined by the dimensions of the ensonified volume in each direction $\left(\Delta X_{V}, \Delta Y_{V}\right.$, $\left.\Delta Z_{V}\right)$, which depend upon the range from the TVSS (R), the transmitted beamwidth $\left(\theta_{T}\right)$, the receive beamwidth $\left(\theta_{R}\right)$, and the beam angle $(\theta)$.

the unique synoptic three-dimensional perspective afforded by this sonar system to explore and characterize the spatial and temporal structure of pelagic fish schools and the patchiness of epipelagic zooplankton found in the northeastern Gulf of Mexico. The data were collected during engineering tests of the TVSS conducted by the U.S. Navy's Coastal System Station, Panama City, FL, in a $2-\mathrm{nm}^{2}$ area centered at $29^{\circ} 30^{\prime} \mathrm{N}, 86^{\circ} 30^{\prime} \mathrm{W}$. This is a relatively flat area on the continental shelf, with water depths ranging from 190 to $200 \mathrm{~m}$, situated roughly $65 \mathrm{~nm}$ southwest of Panama City, and 20 $\mathrm{nm}$ southeast of De Soto Canyon.

The TVSS includes separate cylindrical projector and hydrophone arrays, with the same $0.53-\mathrm{m}$ diameter, mounted coaxially on a cylindrical tow body. The projector array has 32 elements equally spaced 11.25 degrees apart around the cylinder and designed to produce a "toroidal" beampattern that is meant to be omni-directional in the plane perpendicular to the cylinder's axis (usually across-track) and 3.7 degrees wide at $-3 \mathrm{~dB}$ in any plane containing the cylinder's axis (usually along-track). The hydrophone array consists of 120 elements equally spaced every 3 degrees around the cylinder. In the work presented here, beamforming of the hydrophone array yielded 120 receive beams, each 4.95 degrees wide at $-3 \mathrm{~dB}$ and spaced 3 degrees apart to cover the full 360 degrees around the array in the plane perpendicular to the array's axis.

Using this multibeam geometry, we have adapted existing oceanic imaging techniques to construct acoustic backscatter imagery of horizontal and vertical planes in the ocean volume (Fig. 1). Only vertical imagery is presented in this study to characterize the spatial distributions of bioacoustic scatterers and to partially discriminate between desired bioacoustic signals and volume or boundary reverberation. This is not possible with conventional single- or dual-beam echosounders because of the temporal lags introduced by the successive transects required to cover a volume of ocean comparable to that sampled by the multibeam sonar on one track. However, multibeam echo-sounders have important limitations due to the beamforming process and our intent is to demonstrate some of the capabilities and limitations of multibeam sonars in bioacoustic applications.

We begin by describing the TVSS data and signal processing methods that help to interpret the acoustic backscatter images. Because net tow or trawl samples were not collected in parallel with the acoustic data, our interpretations of these images rely on comparison and reference to previous biologic surveys in the northeastern Gulf of Mexico, and on the general bioacoustic literature.

\section{TVSS DATA}

\section{A. Data collection}

The acoustic data presented here were collected on 9 November 1994 between 1026AM and 1131AM local time. The wind speed and sea state recorded at 0658AM were 6 knots $(3 \mathrm{~m} / \mathrm{s})$ and 1.5 , respectively. A CTD cast, taken at 0658AM approximately $100 \mathrm{~m}$ north of the location for run 1 (Fig. 2), revealed the presence of a $24.8^{\circ} \mathrm{C}$ isothermal mixed layer extending to a depth of $49 \mathrm{~m}$, a thermocline between 49 and $150 \mathrm{~m}$ depth, and a nearly isothermal layer above the bottom with a temperature of $15.6^{\circ} \mathrm{C}$. The surface salinity was $35.1 \mathrm{PSU}$, and the surface sound speed was $1534 \mathrm{~m} / \mathrm{s}$. Historical data indicate a relatively weak circulation in the region during fall months, ${ }^{15}$ which, with the light winds, suggests that the surface currents were either weak or absent. 
TVSS Deployment -- 09 Nov 94

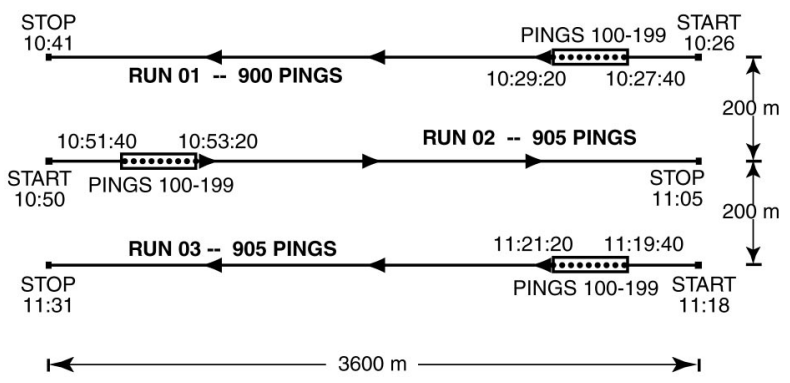

FIG. 2. TVSS track lines for three consecutive runs. The data presented in this paper are processed from pings 100-199 in each of the three runs. In the figure, north is upward.

The TVSS was towed at a depth of $78 \mathrm{~m}$, approximately $735 \mathrm{~m}$ astern a ship moving at a nearly constant speed of 4.1 $\mathrm{m} / \mathrm{s}$. Three runs of 100 consecutive pings of acoustic backscatter data, from a $200 \mu \mathrm{s} \mathrm{CW}$ pulse of $68 \mathrm{kHz}$ transmitted at $1 \mathrm{~Hz}$ recorded during the tests, are analyzed here. Towfish roll, pitch, heading, speed, and depth were sampled at $1 \mathrm{~Hz}$ (once per ping). Further information regarding the TVSS, the data collection, and the signal processing is described in Ref. 16.

\section{B. Environmental context}

Because we lacked the net tow and trawl data required to verify that biologic sources are responsible for scattering features seen in our data, we rely on historical and concurrent data for evidence. The abundance and distribution of pelagic fish in the Gulf of Mexico (GOM) were investigated by the US National Marine Fisheries Service (NMFS) during 15 cruises in the spring and fall seasons between 1988 and 1996. ${ }^{17}$ Trawling was performed only during daylight hours near the bottom, with the highest concentration of sampling stations centered approximately $10 \mathrm{~nm}$ northwest of the TVSS experiment site. For several species, the highest abundances were sampled at four sites within $1 \mathrm{~nm}$ of the TVSS experiment site. Thus, the NMFS survey encompassed the year, season, time of day, geographic location, and depth corresponding to the collection of the TVSS acoustic data.

Zooplankton species known to scatter sound near 68 $\mathrm{kHz}$, such as euphausiids, have been observed in the northeastern and central GOM as well. Hopkins' observations in a region about $120 \mathrm{~nm}$ south of the TVSS experiment showed that zooplankton biomass was concentrated in the upper 50 $\mathrm{m}$ of the water column. ${ }^{18}$ Zimmerman and Biggs observed acoustic scattering due to zooplankton in warm- and coldcore eddies in the eastern central GOM during June 1995 using a $153-\mathrm{kHz}$ acoustic Doppler current profiler. ${ }^{19}$ Also in the eastern central GOM, Hopkins et al. examined the landward distributions of zooplankton between May and June 1977, and found many oceanic species distributed across the Florida shelf. ${ }^{20}$ Ortner et al. investigated the vertical distributions of zooplankton during January and February 1981, and found zooplankton distributions to be closely tied to mixed layer depth. ${ }^{21}$ Ortner et al. reported observations of euphausiids and decapod shrimp in a region about $50 \mathrm{~nm}$ southeast of the TVSS experiment site. ${ }^{22}$

\section{Processing methods}

The processing scheme that we have developed for the TVSS acoustic data is designed for conformal arrays and includes quadrature sampling, resampled amplitude shading, element-pattern compensation, and broadside beamforming on phase-compensated, overlapping subarrays with asymmetric projected element spacings. ${ }^{23}$ This procedure permits split aperture processing of the beamformed output, which is performed because the processed data also were used to study acoustic backscatter from the ocean boundaries, and the phase zero-crossing of the output phasor is the most accurate means to detect the arrival time of boundary reflections on the maximum response axis of the beam. ${ }^{24,25}$

For each ping, the split aperture process is used to form a phasor $P(\theta, t)$ for a given beam direction $\theta$ and time sample $t$ every 3 degrees for directions spanning the 360 degrees around the TVSS axis. The magnitude of $P(\theta, t)$ has units of volts ${ }^{2}$, and is converted to squared echo amplitude according to

$$
\begin{aligned}
10 \log _{10}\left(\mathrm{EL}^{2}(\theta, t)\right)= & 10 \log _{10}\left(\frac{1}{2}|P(\theta, t)|\right) \\
& -\mathrm{RVR}-\mathrm{FG}-\mathrm{DI}-\mathrm{TVG},
\end{aligned}
$$

where $\mathrm{RVR}=-168 \mathrm{~dB} r e: 1 V_{\mathrm{rms}} / \mu \mathrm{Pa}$ is the receive voltage response of each hydrophone, $\mathrm{FG}=29 \mathrm{~dB}$ is the preamplifier fixed gain, $\mathrm{DI}=13 \mathrm{~dB}$ is the array gain associated with the beamforming and split aperture processing, and TVG is the system time-varying gain. The left side of Eq. (2) is equivalent to the plane wave reverberation level (RL) in the active sonar equation, ${ }^{4}$ which we use to compute volume scattering strength:

$$
\begin{array}{r}
S_{V}=\mathrm{RL}-\mathrm{SL}+2 \mathrm{TL}-10 \log _{10} V \\
\text { with } \mathrm{TL}=20 \log _{10} R+\alpha R,
\end{array}
$$

where $R$ is the range from the TVSS determined from $t$ and $\theta$ using constant gradient ray-tracing techniques, SL $=216.8 \mathrm{~dB}$ re:1 $\mu \mathrm{Pa} @ 1 \mathrm{~m}$ is the calibrated TVSS source level, $\alpha=0.024 \mathrm{~dB} / \mathrm{m}$, and $V$ is the volume ensonified by the transmitted pulse within the receive beam.

Volume scattering strength images were constructed by first computing $S_{V}$ from Eqs. (2) and (3) for each beamformed sample in each ping, yielding 120 backscattering strength times series. These may be displayed together as a vertical slice of volume acoustic scattering strength in polar coordinates of angle versus time (Fig. 3). In this representation, echoes from the sea surface and seafloor appear as the high backscatter, horizontal features. Scattering from resonant microbubbles in the towship's wake and from bubble clouds formed by breaking ship waves are responsible for the high backscattering strength features near the sea surface. Other scattering structures are apparent upon adjusting the dynamic range of the display, and these will be discussed in Sec. III.

Volume scattering strength images in the plane parallel to the towfish's direction of travel were formed by extracting $S_{V}$ data recorded over successive pings. Echo-integrated vertical volume backscattering strength images on either side of 


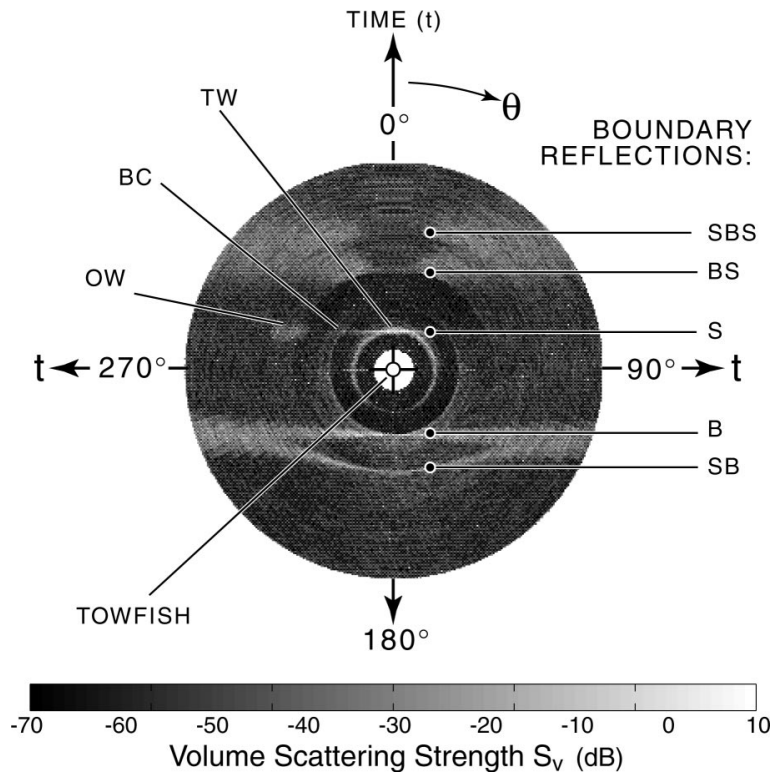

FIG. 3. One TVSS ping displayed as a vertical slice of acoustic volume scattering strength $\left(S_{V}\right)$ in polar coordinates of angle versus two-way travel time $(t)$. Labels refer to the following features: TW-towship's wake; OW-towship's wake generated during previous run; $\mathrm{BC}$-bubble cloud generated by a breaking bow wave from the towship; B-seafloor echo; $\mathrm{S}$ - sea surface echo; SB-surface-bottom (multiple) echo; BS-bottomsurface (multiple) echo; SBS-surface-bottom-surface (multiple) echo. The maximum two-way travel time $t$ represented by the data in this figure is 0.54 s.

the towfish were constructed with a time gate $\delta t$ corresponding to a 1.4-m depth interval, and an along-track averaging interval of three pings.

\section{TVSS beam geometry}

The sampling and resolution characteristics of the backscattering strength images are determined by the acoustic geometry of each TVSS ping. The angular sample spacing between the maximum response axes of adjacent beams in Fig. 3 is $\theta_{s}=3$ degrees, whereas the quadrature sampled time increment within each beam is $\tau_{s}=160 \mu \mathrm{s}$, which corresponds to a $12-\mathrm{cm}$ sampling interval assuming a sound speed in seawater $c=1500 \mathrm{~m} / \mathrm{s}$. With the TVSS pulse length $\tau_{p}$ $=200 \mu \mathrm{s}$, the bandwidth $W=0.88 / \tau_{p}=4.4 \mathrm{kHz}$ yields a nominal range resolution $\Delta R=c / 2 W=17 \mathrm{~cm}$.

The volumetric resolution in each ping is determined by the spatial dimensions of the volume $(V)$ ensonified by the TVSS transmit pulse within each receive beam (Fig. 1). We compute $V$ as the ellipsoidal shell section formed from the intersection of the pulse, the transmit beam pattern, and the receive beam pattern at each sampling point:

$$
V=\frac{2}{3} \theta_{T} \sin \left(\theta_{R} / 2\right)\left[R^{\prime 3}-R^{3}\right] \quad\left(\mathrm{m}^{3}\right),
$$

where $R$ is the range from the center of the TVSS in meters, $R^{\prime}=R+\Delta R$, the $-3-\mathrm{dB}$ receive beamwidth $\left(\theta_{R}\right)$ is 4.95 degrees, and the $-3-\mathrm{dB}$ transmit beamwidth $\left(\theta_{T}\right)$ is 3.7 degrees. The spatial dimensions of $V$ in the across-track, alongtrack, and vertical dimensions $\left(\Delta x_{V}, \Delta y_{V}, \Delta z_{V}\right.$, Fig. 1) vary with range. The along-track dimension is the same for all beam angles $\theta$ :

$$
\Delta y_{V}=2 R^{\prime} \sin \left(\theta_{T} / 2\right) .
$$

However, the across-track and vertical dimensions of $V$ vary with range and $\theta_{a}$, which is defined in relation to $\theta$ in Fig. 1 as $\theta_{a}=\theta$ for $\theta=0$ to 90 degrees; $\theta_{a}=|180-\theta|$ for $\theta=91$ to 270 degrees; and $\theta_{a}=(360-\theta)$ for $\theta=271$ to 359 degrees. Thus, for volume cells in beams directed towards zenith and nadir, ( $\theta_{a}=0$ degrees)

$$
\begin{aligned}
& \Delta x_{V}=2 R^{\prime} \sin \left(\theta_{R} / 2\right) \quad(\mathrm{m}), \\
& \Delta z_{V}=\Delta R+R\left(1-\cos \left(\theta_{R} / 2\right)\right) \quad(\mathrm{m}),
\end{aligned}
$$

and for volume cells in horizontal beams, ( $\theta_{a}=90$ degrees)

$$
\begin{aligned}
& \Delta x_{V}=\Delta R+R\left(1-\cos \left(\theta_{R} / 2\right)\right) \quad(\mathrm{m}), \\
& \Delta z_{V}=2 R \sin \left(\theta_{R} / 2\right) \quad(\mathrm{m}),
\end{aligned}
$$

where $\Delta x_{V}$ exceeds the range resolution at $\theta_{a}=90$ degrees, and $\Delta z_{V}$ exceeds $\Delta R$ at $\theta_{a}=0$ degrees because of the curvature of the wavefront. For angles between the horizontal and vertical, the $x$ and $z$ dimensions of $V$ can be expressed as

$$
\begin{aligned}
\Delta x_{V}= & 2 R \sin \left(\theta_{R} / 2\right) \cos \theta_{a}+\Delta R \sin \left(\theta_{a}+\theta_{R} / 2\right), \\
\Delta z_{V}= & 2 R \sin \left(\theta_{R} / 2\right) \sin \theta_{a}+\Delta R \cos \left(\theta_{a}-\theta_{R} / 2\right) \\
& \text { for } 0<\theta_{a}<90-\theta_{R} / 2 .
\end{aligned}
$$

Samples in adjacent beams overlap because $\theta_{s}<\theta_{R} / 2$. The overlapping volume increases with range:

$$
\begin{aligned}
V_{\mathrm{ol}}= & \frac{2}{3} \theta_{T} \sin \left(\left(\theta_{R}-\theta_{s}\right) / 2\right)\left[R^{\prime 3}-R^{3}\right] \quad\left(\mathrm{m}^{3}\right) \\
& (\text { adjacent beams })
\end{aligned}
$$

whereas the percent overlapping volume is

$$
\mathrm{VP}_{\mathrm{ol}}=\left[\sin \left(\left(\theta_{R}-\theta_{s}\right) / 2\right) / \sin \left(\theta_{R} / 2\right)\right] \times 100 \%
$$$$
\text { (adjacent beams), }
$$

yielding a range-independent volume overlapping percentage of $39.4 \%$ between adjacent TVSS beams within the same ping. Volumes ensonified on successive pings in the same beam angle overlapped and increased with range beyond 62 $\mathrm{m}$ due to the towfish's speed of $V_{\mathrm{tvss}}=4.1 \mathrm{~m} / \mathrm{s}$ and $-3-\mathrm{dB}$ transmit beamwidth $\theta_{T}=3.7$ degrees.

The backscatter images in this study were constructed using the sidescanning techniques described in Ref. 24, where samples of acoustic backscatter are extracted for the time and angle pairs that correspond to the desired horizontal or vertical plane (Fig. 1). Between discrete beam angles, samples are interpolated in time increments corresponding to the quadrature sampling interval $\tau_{s}$. Thus, the sample spacings in the images depend upon $\tau_{s}$, as well as $R, V_{\mathrm{tvss}}$, and $\theta_{a}$. The along-track sample spacing is the ping separation distance $\delta y_{V}=\Delta y_{\text {ping }}$, whereas across-track and vertical sample spacings are

$$
\begin{array}{ll}
\delta x_{V}=c \tau_{s} / 2 \sin \theta_{a}, & (\mathrm{~m}) \text { for } \theta_{a}>\theta_{R}, \\
\delta z_{V}=c \tau_{s} / 2 \cos \theta_{a}, & \text { (m) for } \theta_{a}<90^{\circ}-\theta_{R} .
\end{array}
$$

A consequence of the sidescanning procedure is that the number of samples per beam angle increases as $\theta_{a}$ decreases. 


\section{E. System-related sources of error}

A large source of error in our measurements was the angular variation in the transmitted beampattern. A maximum deviation of $-9 \mathrm{~dB}$ from the calibrated source level existed when hydrostatic tests were performed on the TVSS a year before the data collection. We were unable to correct for these variations because the actual beampattern may have changed slightly during the year between the hydrostatic testing and the TVSS deployment. ${ }^{24}$

The beampatterns of the 120 individual hydrophones introduced another source of error, because they were not identical, and their RVRs, FGs, and TVGs varied as much as \pm 2 $\mathrm{dB}$ from average values. To simplify the beamforming, we used an average of the calibrated hydrophone sensitivity values of $-168 \mathrm{~dB}$ re: $1 V_{\mathrm{rms}} / \mu \mathrm{Pa}$, and we approximated the beampatterns of individual hydrophones with a cardioidshaped magnitude response that closely matched that provided by the manufacturer. In the absence of hydrophone phase response data, we approximated the phase pattern for each element with a function proportional to the $\sin ^{2}$ of the angle between the maximum response axes of the element and the subarray containing it. We used these response patterns because they successfully removed pointing errors which were observed in previous beamforming efforts with the TVSS. ${ }^{23}$

Computer simulations, which used the TVSS transmit pattern and towfish attitude data for each run, indicated that the TVSS array beampatterns produced a maximum bias error of $-7 \mathrm{~dB}$ and a maximum random error of $\pm 3.3 \mathrm{~dB}$ in the TVSS data. After echo-integrating and averaging over successive pings, these values were reduced to approximately $-5 \mathrm{~dB}$ for the bias error and $\pm 1 \mathrm{~dB}$ for the random error.

Another important limitation of the data presented here is that boundary echoes at normal incidence $(\theta=0$ or 180 degrees, Fig. 3), received through the sidelobes of beams directed towards the volume, contaminated the volume backscatter received in their mainlobes. This problem is illustrated in the returns for a single ping (Fig. 3) and for a 97-ping average [Fig. 4(a)], where boundary echoes appear as high backscatter circular features tangent to the sea surface and seafloor.

The linear bands extending diagonally from the bottom into the volume in Fig. 4(a) also result from bottom sidelobe returns. We verified through computer simulations that their unique structure is a consequence of the uniform 3-degree spacing between the receive beams, and of the nonuniform sidelobe spacing within each receive beampattern. The simulation results appear in Fig. 4(b) as dashed lines that match closely the underlying linear bands and represent the times and angles of each volume beam with a sidelobe directed at the bottom during the time of the bottom echo arrival. Minor differences probably result from uncertainties in the towfish's attitude. ${ }^{24}$

This sidelobe interference is somewhat enhanced by our choice of a resampled Dolph-Chebyshev amplitude shading window designed to produce a nearly uniform sidelobe level between -28 and $-30 \mathrm{~dB}$ for all the receive beampatterns. ${ }^{23}$ Lower sidelobe levels are achievable, but the corresponding
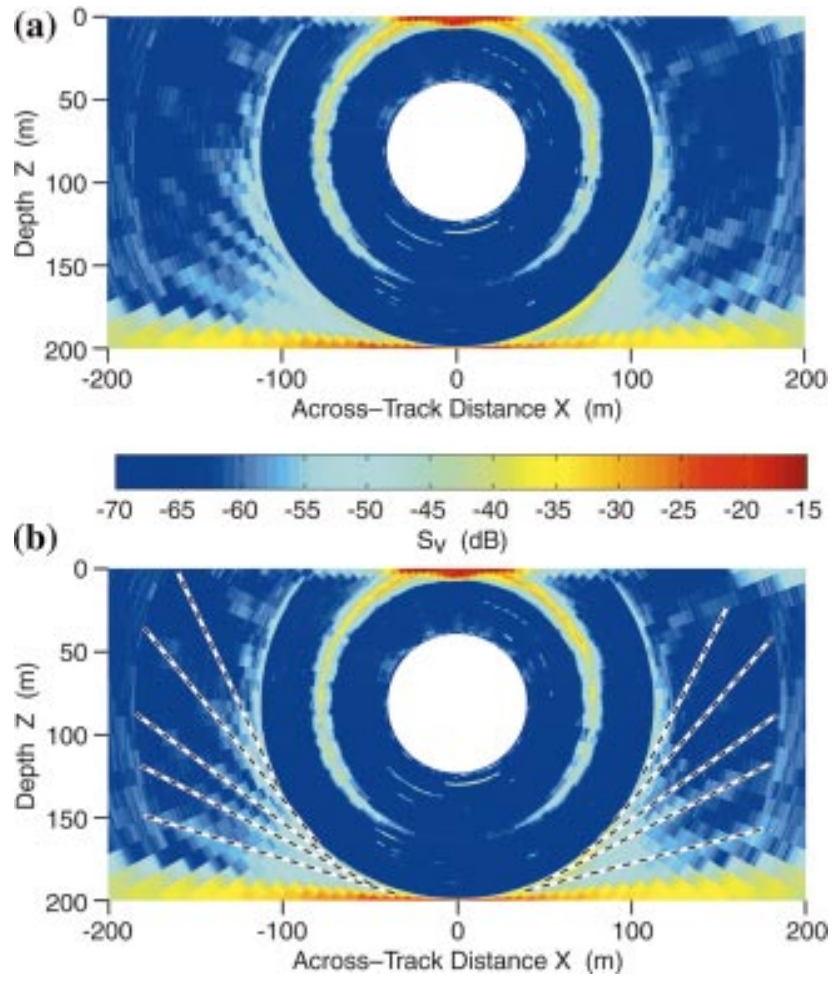

FIG. 4. (a) and (b) Average volume acoustic scattering strength of 97 pings collected during run 2. (b) Computer simulations determined the time-angle pairs (dashed lines) for which a sidelobe of a beam pointing in the ocean volume was directed towards the bottom at the time of arrival of each bottom echo.

increase in mainlobe beam width would degrade the spatial resolution in the images. Due to the strong boundary echo sidelobe returns in the TVSS data, sidelobe cancellation methods are necessary to use data in the upward looking beams beyond slant ranges equal to the towfish's depth $(\sim 78$ $\mathrm{m}$ ), and in the downward looking beams beyond slant ranges equal to the towfish's altitude $(\sim 115 \mathrm{~m})$.

One additional limitation of the data presented here is the void region with a radius of $\sim 40 \mathrm{~m}$ around the TVSS (Figs. 3 and 4) caused by a fixed 53-ms blanking delay between transmission and the start of digitization. This was done because the TVSS deployment was conducted primarily to evaluate the sonar's mine-detection capability between 50 and $750 \mathrm{~m}$, so the void region helped to reduce the large amount of data collected by the sonar. This feature of the TVSS is not a problem for future bioacoustic applications because the time interval between transmit and receive is adjustable, so that the void region may be reduced.

\section{IMAGERY RESULTS AND INTERPRETATION}

\section{A. Fish schools}

Along-track images [Figs. 5(a) and (c)] were formed by using a vertical echo-sounding procedure to extract backscatter data in the down-looking beams at each along-track sampling point. Across-track sections [Figs. 5(b) and (d)] were formed by using the same procedure as that used to create Fig. 3. Based on the nearly concurrent NMFS trawl data, the prominent backscatter features centered at $(y=285 \mathrm{~m}, z$ $=190 \mathrm{~m})$ in Fig. 5(a) and $(y=340 \mathrm{~m}, z=200 \mathrm{~m})$, in Fig. 


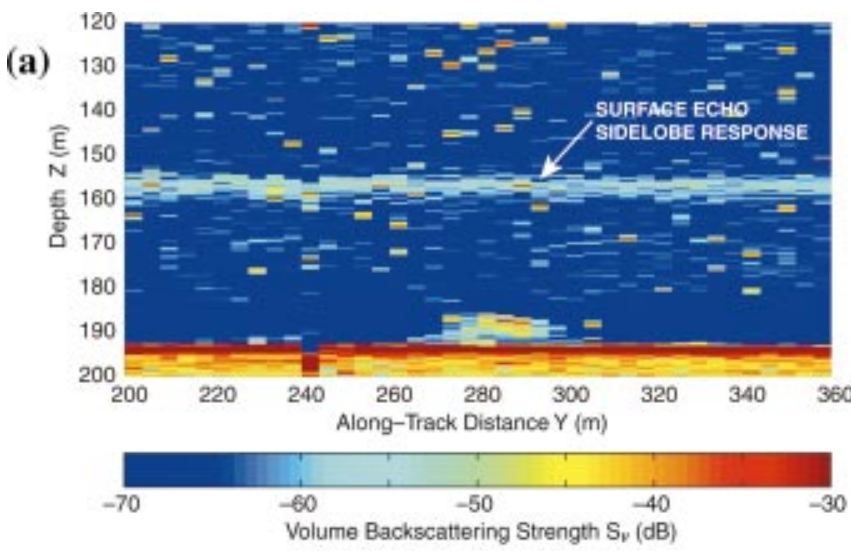

(c)


FIG. 5. Vertical volume acoustic backscattering strength $\left(S_{V}\right)$ images of two near bottom fish schools in run 1 [(a), (b)], and run 2 [(c), (d)]. The seafloor is the high backscatter, horizontal feature at $z=193 \mathrm{~m}$ in (a) and (b), and $202 \mathrm{~m}$ in (c) and (d). The horizontal feature with moderately high backscatter at 158 - $\mathrm{m}$ depth in (a) is the sidelobe response of the sea surface echo, seen also in the individual (Fig. 3) and averaged (Fig. 4) ping data. The randomly distributed samples in (a) where $S_{V}>-40 \mathrm{~dB}$ in the water column are signals that were saturated in the TVSS data acquisition system electronics. These appear as the thin arcs in Fig. 5(b) above and below the sea surface echo sidelobe return.

5(c) are attributed to schools of small pelagic fish. Together, the orthogonal image pairs in Fig. 5 characterize the size and scattering characteristics of the two fish schools (Table I). Although the images are limited by surface echo sidelobe interference and saturated samples, these artifacts were distinguished from biologic scatters by their arclike across-track structure [Figs. 5(b) and (d)]. Had we only constructed the along-track sections [Figs. 5(a) and (c)], these samples might have been incorrectly attributed to the acoustic backscatter from individual fish.

TABLE I. Fish school data corresponding to Figs. 5 and 6. The seafloor backscattering strength $S_{B}$ was computed and analyzed in Ref. 24 . The target strength (TS) values are for ensonified volumes, and not individual fish.

\begin{tabular}{lcc}
\hline \hline & Run 1 & Run 2 \\
\hline Maximum height above seafloor (m) & 7.1 & 4.7 \\
Maximum along-track dimension (m) & 42 & 32 \\
Maximum across-track dimension (m) & 31 & 26 \\
Maximum TS (dB) & -24.3 & -28.9 \\
Mean TS (dB) & -45.5 & -47.3 \\
Maximum $S_{V}(\mathrm{~dB})$ & -31.9 & -40.1 \\
Mean $S_{V}(\mathrm{~dB})$ & -56.1 & -59.8 \\
Mean $S_{B}(\mathrm{~dB})$ at normal incidence & -8.0 & -9.7 \\
Standard deviation of $S_{B}(\mathrm{~dB})$ at normal incidence & 2.3 & 2.0 \\
Normal incidence $S_{B}(\mathrm{~dB})$ below fish school & -8.1 & -9.9 \\
\hline \hline
\end{tabular}

We constructed a 3D shape representation of the school in Figs. 5(a) and (b) by processing multiple along-track $(x, z)$ sections over successive pings. Bottom detection processing was used first to discriminate between acoustic backscatter from the seafloor and from the school. ${ }^{24} \mathrm{~A}$ threshold of $5 \mathrm{~dB}$ over the ambient scattering strength level was applied to detect samples in the school, and their corresponding $(x, y, z)$ positions were determined using constant gradient ray tracing. The result [Fig. 6(a)] resembles a "stack" of elongated "tubes" extending across-track, with a few apparently suspended above the "stack." These features are a consequence of the TVSS sampling and resolution characteristics that are fundamental limitations for any sonar (cf. Ref. 7). The resolution of each sample is defined by the spatial dimensions of the ensonified volume [Fig. 1(c)], which are $\Delta x_{V}=9.9 \mathrm{~m}$, $\Delta y_{V}=7.4 \mathrm{~m}$, and $\Delta z_{V}=0.28 \mathrm{~m}$ at the school's center. Therefore, the elongated features in Fig. 6(a) are most likely returns from individual fish above the center of the school, because ensonified volumes in adjacent beams overlap by $39.4 \%$, and beams adjacent to those directed towards large scatterers or boundaries exhibit a significant sidelobe response. Sidelobe response from the fish school appears in Fig. 6(b) as light blue samples at depths of $180-185 \mathrm{~m}, 40 \mathrm{~m}$ across-track on either side of center. These samples are about $5 \mathrm{~dB}$ above the ambient level and immediately precede the arc corresponding to the bottom echo sidelobe response. 

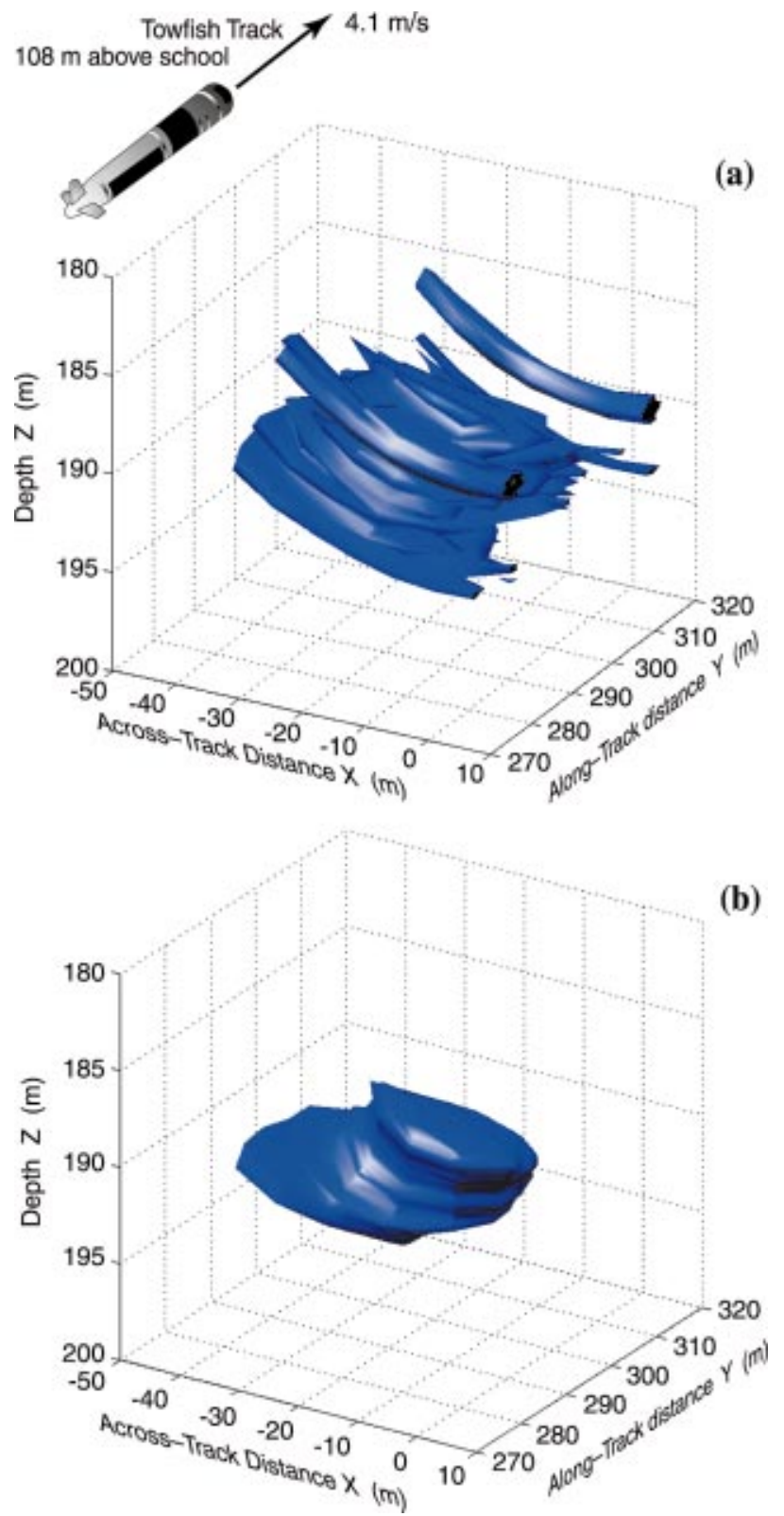

FIG. 6. (a) Three-dimensional representation of the fish school detected in run 1 [Figs. 5(a) and (b)]. The thin, elongated features are volume cells in adjacent, overlapping beams in which fish were detected. (b) Volumetric representation of the school after filtering the samples in and around the school with a $3 \times 3 \times 3$ moving average filter and thresholding the output 5 $\mathrm{dB}$ above the ambient scattering strength values.

To compensate for these artifacts and produce a shape characterization potentially more representative of the actual fish school, a $3 \times 3 \times 3$-sample moving average filter was applied to the scattering strength samples in and around the school. Filtered samples with scattering strengths greater than $5 \mathrm{~dB}$ above the ambient scattering strength were retained, yielding an oblong volumetric shape that extends slightly diagonally to the across-track direction [Fig. 6(b)]. The shape's maximum length is three times its maximum width and over six times its maximum height (Table I). In this representation, the school appears to be concentrated near the bottom, which was generally flat with a mean depth of $193 \mathrm{~m}$ in this run. Although the thresholds and filter dimensions were subjectively chosen and the representation does not account for relative motion between the school and the TVSS, the school shape in Fig. 6(b) is generally similar to those observed for other schools of small pelagic fish near the bottom during daytime (cf. Ref. 26).

With our limited data, we have no way of identifying the species of fish responsible for the enhanced volume acoustic backscatter seen in Fig. 5. However, three species representing $73 \%$ of the total catch between 150 and $200 \mathrm{~m}$ in the NMFS trawls could be considered candidates: the round herring (Etrumeus teres), the rough scad (Trachurus lathami), and the Gulf butterfish (Peprilus burti). The latter is the least likely candidate because it does not have a swimbladder for sizes greater than $75 \mathrm{~mm} .{ }^{27}$ The rough scad is a good candidate because its maximum observed length was $75.8 \mathrm{~cm}$, and there was a tendency for the largest fish of most species to be found deeper than 150-m depth. Nonetheless, we favor the round herring (E. teres) as the most likely candidate because it was the most abundant species caught in the NMFS trawls near the TVSS experiment site and over all stations between 150- and 200-m depths, with an average catch rate of 2341/h for the entire GOM. Similar inferences were made by Nero et al. $^{26}$ in their detailed acoustic study of schooling fish about $3 \mathrm{~nm}$ southwest of the TVSS experiment site with a $38-\mathrm{kHz}$ echo-sounder. They concluded that E. teres was responsible for the features in their acoustic backscatter data because of the tendency of this species to form compact schools near the bottom during the day, and ascend to the middle of the water column and disperse at night.

The acoustic characteristics of the schools in the TVSS data are generally comparable to those expected from small pelagic fish. For example, E. teres lengths recorded during the NMFS survey averaged $13.2 \mathrm{~cm}(L / \lambda=6$ at $68 \mathrm{kHz})$ and had a maximum of $51.2 \mathrm{~cm}$, corresponding respectively to mean and maximum target strengths of -42 and $-31 \mathrm{~dB}$ according to Love's model, ${ }^{28}$ or -49.5 and $-37.5 \mathrm{~dB}$ using Foote' $\mathrm{s}^{29}$ empirical relation for clupeoids (herring and sprat) $\left(\mathrm{TS}=20 \log _{10} L-71.9 \mathrm{~dB}\right)$. The mean and maximum target strengths of ensonified volumes within the two schools (Table I) span these model predictions, suggesting that small pelagic fish within individual volume cells are a possible source for the observed data. However, this is only conjecture because physical capture was not performed during the acoustic data collection.

The two- and three-dimensional (2D/3D) characterizations of near-bottom fish schools derived from the TVSS data demonstrate the potential advantages and limitations of multibeam sonars in fisheries acoustics. Two-dimensional characterizations of schooling, ${ }^{7}$ diel migration ${ }^{30}$ seasonal migration, ${ }^{6}$ and feeding ${ }^{26}$ have been useful in understanding fish behavior. But, as far as we know, the economic and scientific advantages of multibeam sonars for 3D characterization of fish schools have only been suggested and not documented. ${ }^{31}$ Because fish distributions are heterogeneous, further 3D analyses may provide important information about the structure and composition of aggregations not available in $2 \mathrm{D}$ studies. 


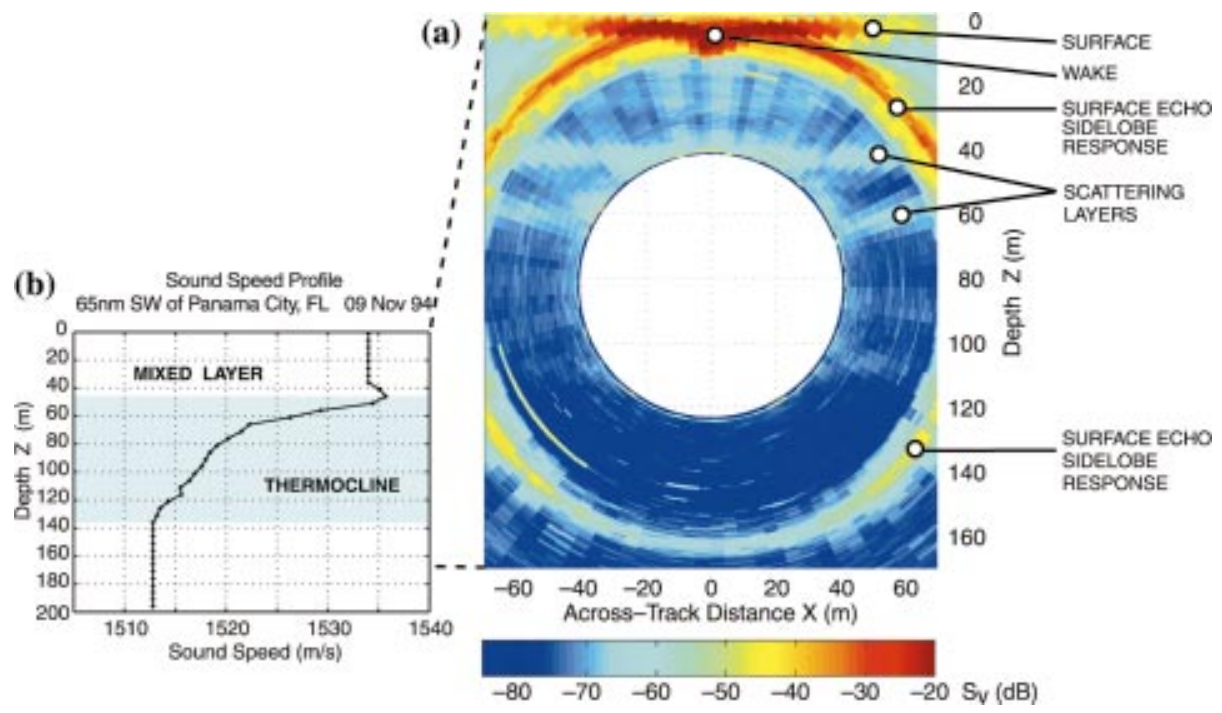

FIG. 7. (a) This 97-ping average for run 2 reveals scattering layers between 40- and 80-m depth. These depths comprised the base of the mixed layer and upper thermocline, which was well described by the sound speed profile (b) obtained $100 \mathrm{~m}$ north of the location for run 1.

\section{B. Volume scattering layers}

We constructed two types of volume backscattering strength images from the TVSS data collected in the middle and upper water column, and both revealed distinct scattering layers in the upper thermocline and at the base of the mixed layer. The first type of these images [Fig. 7(a)] was formed by averaging 97 pings along the length of run 2 (Fig. 2 ). The figure also shows the sidelobe response of the surface echo for beams directed away from zenith, and the high backscatter near zenith due to resonant microbubbles in the towship's wake. ${ }^{25}$

The second type of image consisted of vertical slices of volume acoustic backscattering strength formed along-track on each side of the TVSS by echo-integrating between 30and 130-m depth, and then averaging in three-ping intervals along-track (Fig. 10). In the absence of net and trawl data, historical data suggest that epipelagic zooplankton, and to a lesser extent, micronekton, are the sources for the scattering layers, particularly the previously cited studies which showed that zooplankton distributions in the GOM are centered near the mixed layer depth and upper $50 \mathrm{~m}$ of the water column. ${ }^{18,21}$

Outside the Gulf of Mexico, the results of other acoustic studies using single-frequency sonars near $68 \mathrm{kHz}$ generally support our hypothesis. Pluddemann and Pinkel ${ }^{30}$ observed the diel migration of scattering layers in the eastern North Pacific with a 67-kHz Doppler sonar, and used Johnson's ${ }^{32}$ fluid sphere model to reason that the majority of scattering in their data was due to organisms with equivalent spherical radii 0.1 to $0.4 \mathrm{~cm}$, and lengths 0.5 to $2.0 \mathrm{~cm}$, which includes micronekton and large zooplankton such as decapod shrimp and euphausiids. However, their reasoning assumed that the animals were well described by the fluid sphere model because they also lacked coincident in situ data.

The $70-\mathrm{kHz}$ results of Stanton et al. ${ }^{33}$ are more insightful because they collected mid-water trawl samples and compared them to their acoustic data. The peak scattering strengths in their data were $1-5 \mathrm{~dB}$ lower than those observed during the TVSS experiment (Table II) and were at- tributed to fish or large numbers of arthropods, including euphausiids and shrimp. Their scattering strength predictions were based on Love's ${ }^{34}$ model for fish and Johnson' ${ }^{32}$ model for arthropods and were within $5 \mathrm{~dB}$ of those measured acoustically. Because their scattering strengths were comparable to those measured in the scattering layers by the TVSS, it is likely that the TVSS data also were influenced by zooplankton and micronekton.

One of the largest sources of error in biomass estimates of oceanic zooplankton is their fine-scale patchiness (i.e., spatial variability on scale of $1 \mathrm{~m}$ to $1 \mathrm{~km}$ ), so we examined this aspect of the scattering layers in the TVSS data. Most studies of zooplankton patchiness have relied on onedimensional variance spectra or patch-finding methods, where "patch" is defined by some arbitrary criteria. ${ }^{35,36}$ Wiebe's $\mathrm{s}^{37}$ definition of a patch as "a concentration of individuals exceeding the central value in the data set" implies that patch sizes vary with the length scales covered by the data set, the "window" of samples over which the patch is determined, and the threshold concentration beyond which a patch is defined. Nero and Magnuson ${ }^{36}$ used twodimensional acoustic transects of the Gulf Stream to illustrate the dependencies of patch size and internal patch characteristics on threshold values and window size. With knowledge of the water mass boundaries and characteristics in their data set, they were able to determine the thresholds and window sizes which produced patches that best represented the finescale features of interest. The limited coverage and in situ data in our experiment prevented us from using their approach without a large degree of subjectivity, so we characterized the patchiness of the scattering layer data by estimating the 2D variance spectra from the volume scattering coefficients corresponding to the six $S_{V}$ images in Fig. 8 (see the Appendix).

The average 2D variance spectrum (Fig. 9) reveals the dominant scales of variability in the TVSS scattering layer data. Vertical variability is distributed over a relatively wide portion of the available range of spatial frequencies, with corresponding length scales of $8-33 \mathrm{~m}$. These values are close to the scattering layer thicknesses in Figs. 7 and 8. 
TABLE II. Data computed from the mean profiles of echo-integrated volume scattering strength in Fig. 8, where $x<0 \mathrm{~m}$ was left of the towfish's track. The target strength (TS) values are for ensonified volumes, and not individual scatterers.

\begin{tabular}{|c|c|c|c|c|c|c|}
\hline & \multicolumn{2}{|c|}{ Run 1} & \multicolumn{2}{|c|}{ Run 2} & \multicolumn{2}{|c|}{ Run 3} \\
\hline & $x=-47 \mathrm{~m}$ & $x=47 \mathrm{~m}$ & $x=-47 \mathrm{~m}$ & $x=47 \mathrm{~m}$ & $x=-47 \mathrm{~m}$ & $x=47 \mathrm{~m}$ \\
\hline \multicolumn{7}{|c|}{ Layer 1} \\
\hline depth (m) & $\cdots$ & $\cdots$ & 30 & 31 & 33 & 35 \\
\hline thickness (m) & $\cdots$ & $\cdots$ & 9 & 11 & 14 & 18 \\
\hline $\operatorname{maximum} S_{V}(\mathrm{~dB})$ & $\cdots$ & $\cdots$ & -67.5 & -64.1 & -63.2 & -64.1 \\
\hline depth of maximum $S_{V}(\mathrm{~m})$ & $\cdots$ & $\cdots$ & 29 & 35.5 & 30 & 30 \\
\hline maximum TS (dB) & $\cdots$ & $\cdots$ & -62.3 & -58.5 & -57.5 & -58.0 \\
\hline depth of maximum TS (m) & $\cdots$ & $\cdots$ & 29 & 35.5 & 29 & 30 \\
\hline \multicolumn{7}{|c|}{ Layer 2} \\
\hline depth (m) & 40 & 41 & 47 & 49 & 58 & 60 \\
\hline thickness (m) & 28 & 25 & 21 & 16 & 29 & 22 \\
\hline $\operatorname{maximum} S_{V}(\mathrm{~dB})$ & -61.5 & -61.5 & -64.1 & -63.5 & -61.5 & -62.0 \\
\hline depth of maximum $S_{V}(\mathrm{~m})$ & 49 & 33 & 50.5 & 53 & 55 & 60 \\
\hline maximum TS (dB) & -62.1 & -56.3 & -59.5 & -59.5 & -57.4 & -58.1 \\
\hline depth of maximum TS (dB) & 39 & 33 & 50.5 & 53 & 50.5 & 60 \\
\hline \multicolumn{7}{|c|}{ Layer 3} \\
\hline depth (m) & 70 & 76 & 70 & 74 & $\cdots$ & $\cdots$ \\
\hline thickness (m) & 27 & 22 & 23 & 22 & $\cdots$ & $\cdots$ \\
\hline $\operatorname{maximum} S_{V}(\mathrm{~dB})$ & -59.5 & -59.0 & -64.4 & -66.2 & $\cdots$ & $\cdots$ \\
\hline depth of maximum $S_{V}(\mathrm{~m})$ & 69 & 81 & 69 & 75 & $\cdots$ & $\cdots$ \\
\hline maximum TS (dB) & -56.5 & -56.5 & -61.5 & -64.3 & $\cdots$ & $\cdots$ \\
\hline depth of maximum TS (m) & 69 & 81 & 69 & 75.5 & $\cdots$ & $\cdots$ \\
\hline
\end{tabular}

Horizontal variability is confined to a relatively narrow portion of the range of available spatial frequencies, with corresponding length scales of 30-100 m. These values are consistent with other upper water column observations of zooplankton patch lengths (cf. Refs. 36 and 37). The two dominant peaks in the region near the horizontal spatial frequency $(\mu)$ of $0.02 \mathrm{~m}^{-1}$ and between the vertical spatial frequencies $(\nu)$ of 0.03 and $0.09 \mathrm{~m}^{-1}$ may indicate a coupling between the vertical and horizontal variability at the dominant horizontal scale of $50 \mathrm{~m}$. Greenlaw and Pearcy ${ }^{38}$ used a $20-\mathrm{kHz}$ sonar to suggest that such a phenomenon affected the distributions of mesopelagic micronekton off Oregon, but they based their hypothesis on separate one-dimensional vertical and horizontal variance spectra. The two-dimensional spectrum in Fig. 9 provides evidence for this type of coupling in the TVSS scattering layer data.

The average variance spectra for each run (Fig. 10) show that the patterns in the individual images are similar, but the magnitudes vary with mean scattering strengths. The spectral levels from imagery on the left side of the TVSS always exceed their counterparts on the right side because a hydrophone on the right side of the TVSS failed during the experiment, yielding a decreased gain on the right side of the array. The spectral levels for run 2 were half an order of magnitude lower than those for runs 1 and 3, suggesting that a larger scale of variability might exist which could not be resolved by the spectra in each run. These differences are most likely due to patches longer than $1 \mathrm{~km}$ because the three parallel runs were roughly $3.6 \mathrm{~km}$ long and spaced 200 $\mathrm{m}$ apart (Fig. 2), and coarse scale $[O(1-100 \mathrm{~km})]$ horizontal patchiness of zooplankton is common. ${ }^{36,39}$
Despite the limitations of boundary echo sidelobe interference, we contend that the multibeam geometry of the TVSS provides a bioacoustic remote sensing capability superior to that of the conventional single beam echo-sounder. Because distributions of marine organisms vary in four dimensions $(x, y, z, t)$, they can be sampled more completely by a multibeam sonar system that provides quasi-synoptic coverage through simultaneous horizontal and vertical soundings.

Multibeam systems such as the TVSS also are perfectly suited for the type of three-dimensional visualizations of biological scattering fields presented in Green et al. ${ }^{40}$ Valuable qualitative and quantitative bioacoustic assessments, which have been mostly studied with single-beam systems, could be obtained from images like those in Fig. 8 with their 2Dpoint-kriging/3D-gridding techniques. TVSS data collected over the same track at various intervals (hours, days, weeks) could be used to characterize the 4D spatiotemporal dynamics of diel migration, interaction with dynamic features, and seasonal migration. In the future, we envision merging the multibeam geometry with a multifrequency or broadband capability to provide information regarding the 4D dynamics of species interactions and community structure that is presently unobtainable.

\section{Mean volume reverberation}

High-frequency acoustical scattering from zooplankton is important in non-bioacoustic applications because it can be a significant component of the total volume reverberation level. To quantify this for the TVSS experiment site, we used 
a) RUN 01
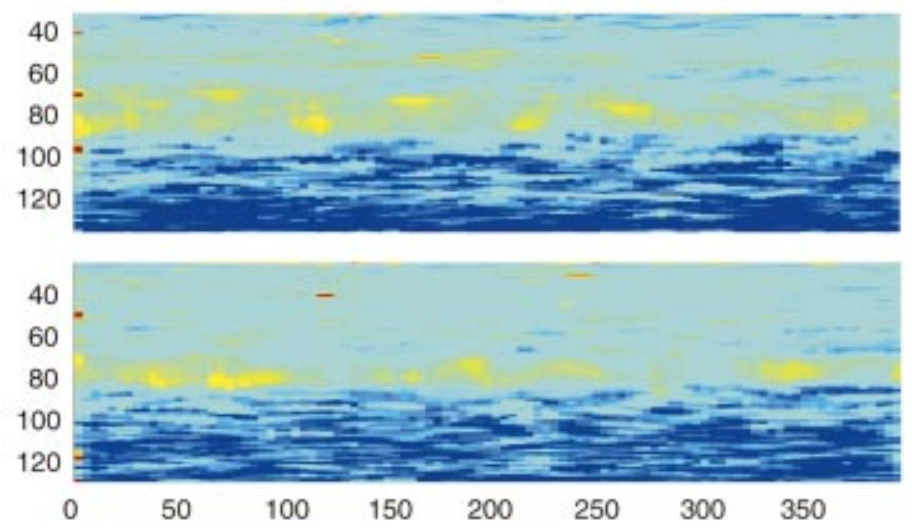

b) RUN 02
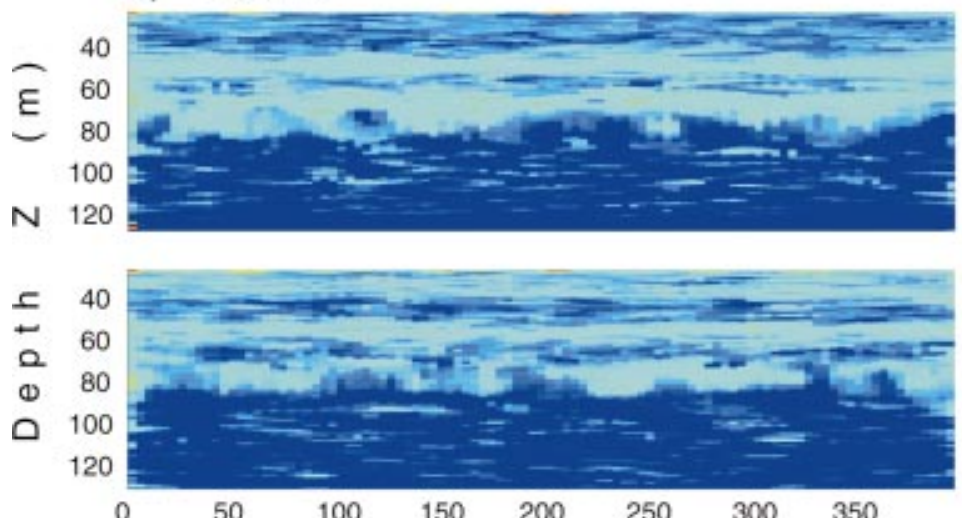

c) RUN 03
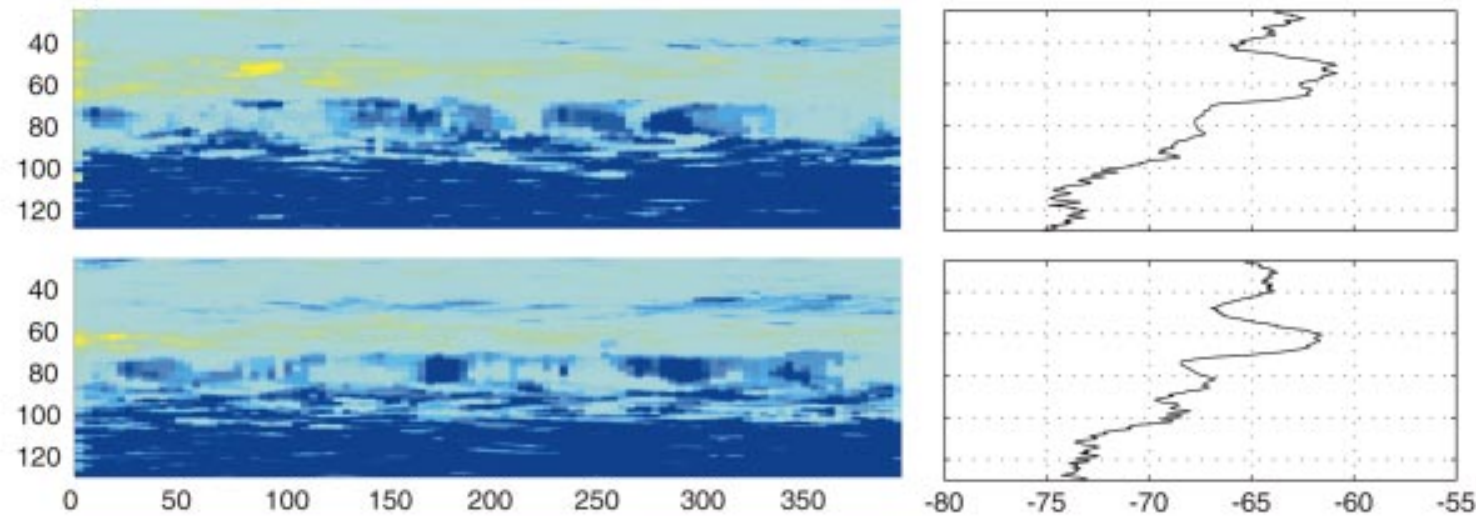

Along - Track Distance $\mathrm{Y}(\mathrm{m})$
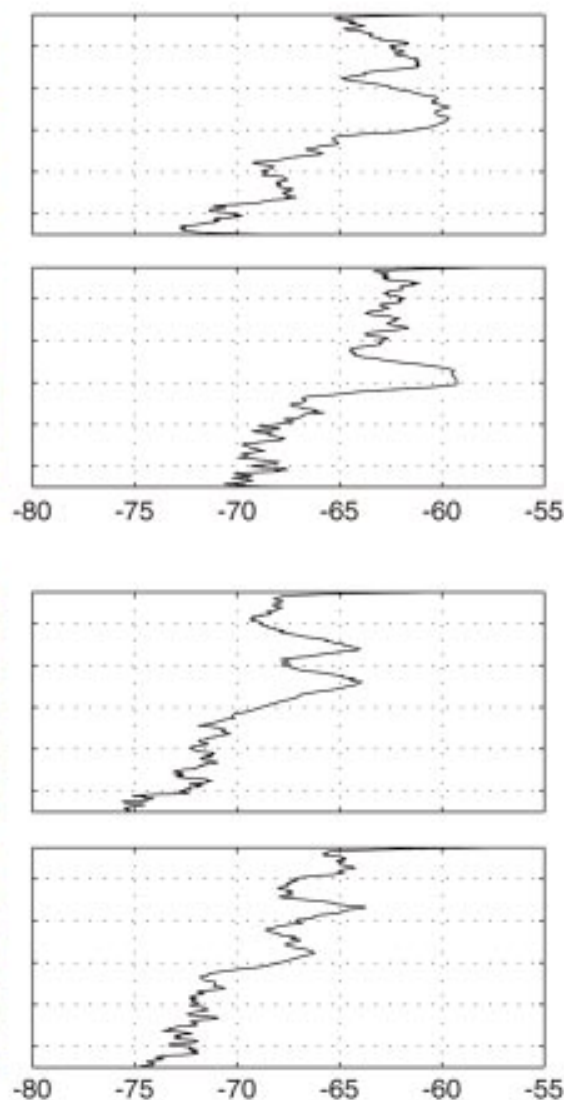

$$
{ }^{55}
$$




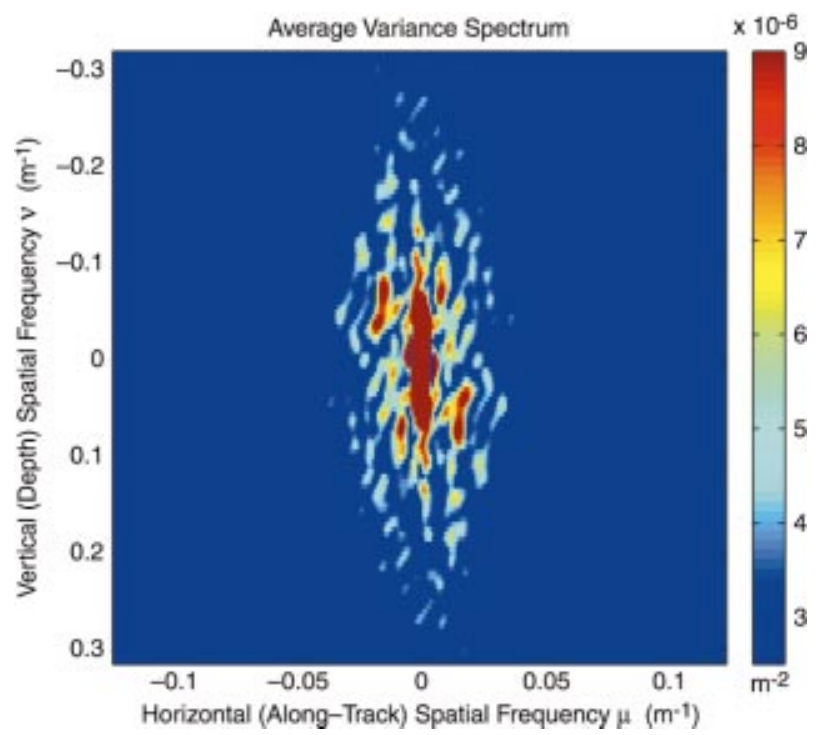

FIG. 9. The average of the six two-dimensional variance spectra of volume scattering coefficients corresponding to the images in Figs. 8(a)-(c). The Appendix describes the calculations, which included a two-dimensional Hanning window to reduce sidelobe leakage. The maximum and minimum length scales resolved are 2.8 and $50 \mathrm{~m}$ in the vertical, and 8 and $205 \mathrm{~m}$ in the horizontal.
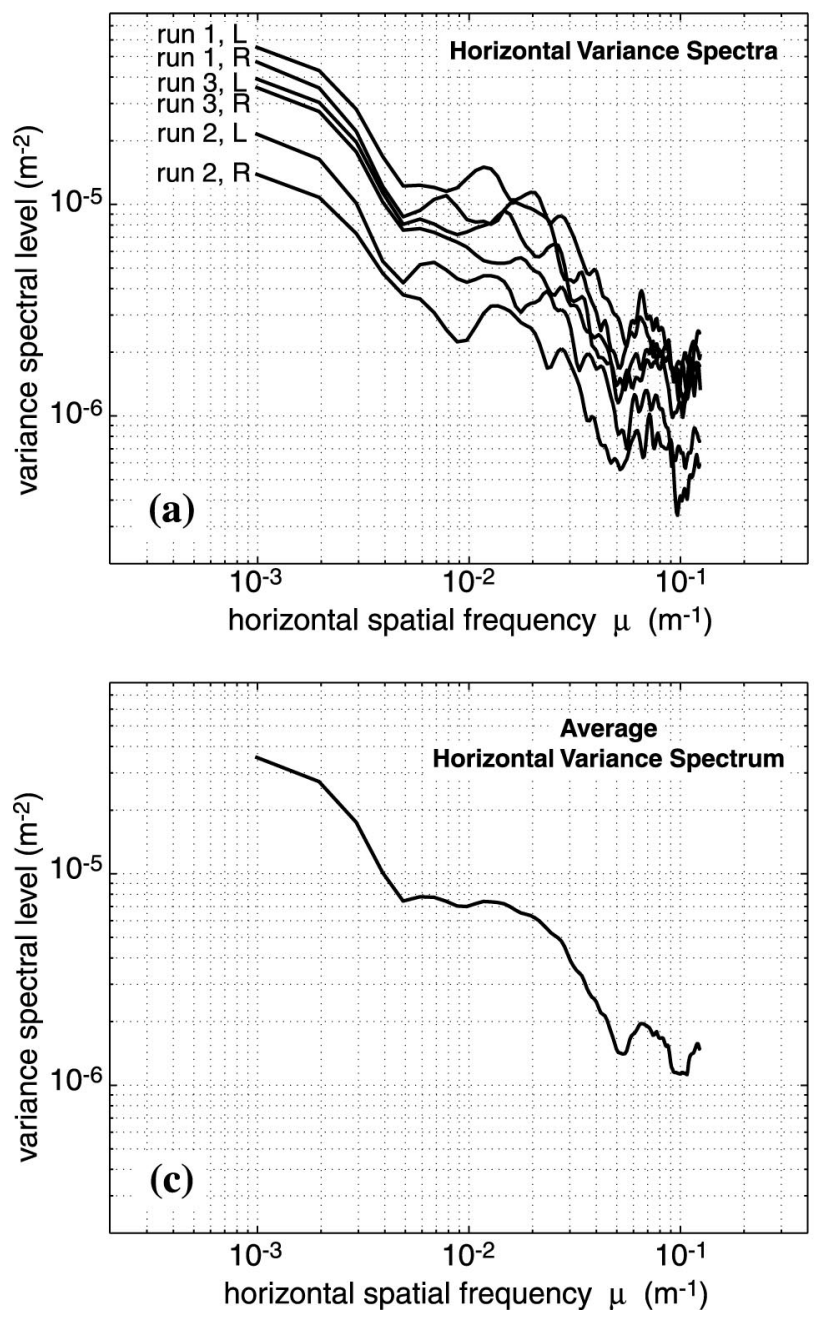

depth, directly above the TVSS are the primary cause for the vertical directionality of the mean volume reverberation levels, as well as the relative peaks near 290 and 70 degrees in each run. The smaller peaks and nulls in $\overline{\mathrm{RL}}$ correspond to peaks and nulls in the transmit beampattern.

Figure 11 directly quantifies the angular-dependent noise floor for non-bioacoustic applications of these TVSS data. The minimum value in the downlooking beams corresponds to a minimum $S_{V}$ measurable by the TVSS of $-75 \mathrm{~dB}$. The plots in Fig. 11 also emphasize that detection near the surface will be more difficult than near the bottom. Although we can expect similar results in many shallow water environments, the shape of $\overline{\mathrm{RL}}$ will vary with changes in scattering layer depths and thicknesses, as well as with the sonar's depth, beampattern, source level, and receiver characteristics. This information is as important in Naval applications (target detection) as in acoustic studies of the sea surface, seafloor, air-sea interaction, and mixing processes. A potential application of the TVSS in a passive mode would be to image the ambient noise field of the sea surface to determine the spatial characteristics of breaking waves and the time variability of the sea surface wave spectrum. ${ }^{41}$
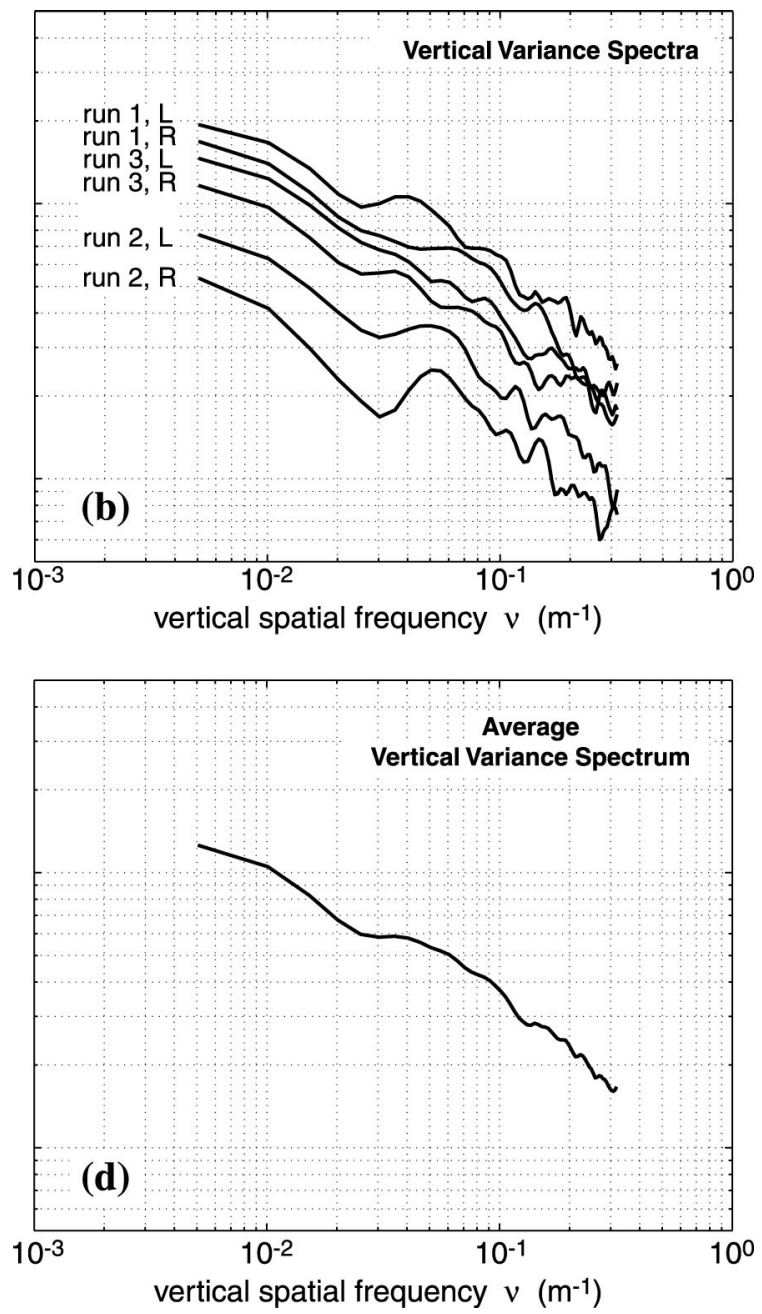

FIG. 10. Log-log plots of (a) horizontal variance spectra averaged over all vertical spatial frequencies in the two-dimensional spectra computed from each image in Fig. 8; L and R refer to images formed $47 \mathrm{~m}$ to the left and right side of the TVSS, respectively; (b) vertical variance spectra averaged over all horizontal spatial frequencies; (c) average horizontal, and (d) vertical variance spectrum computed from (a) and (b), respectively. 


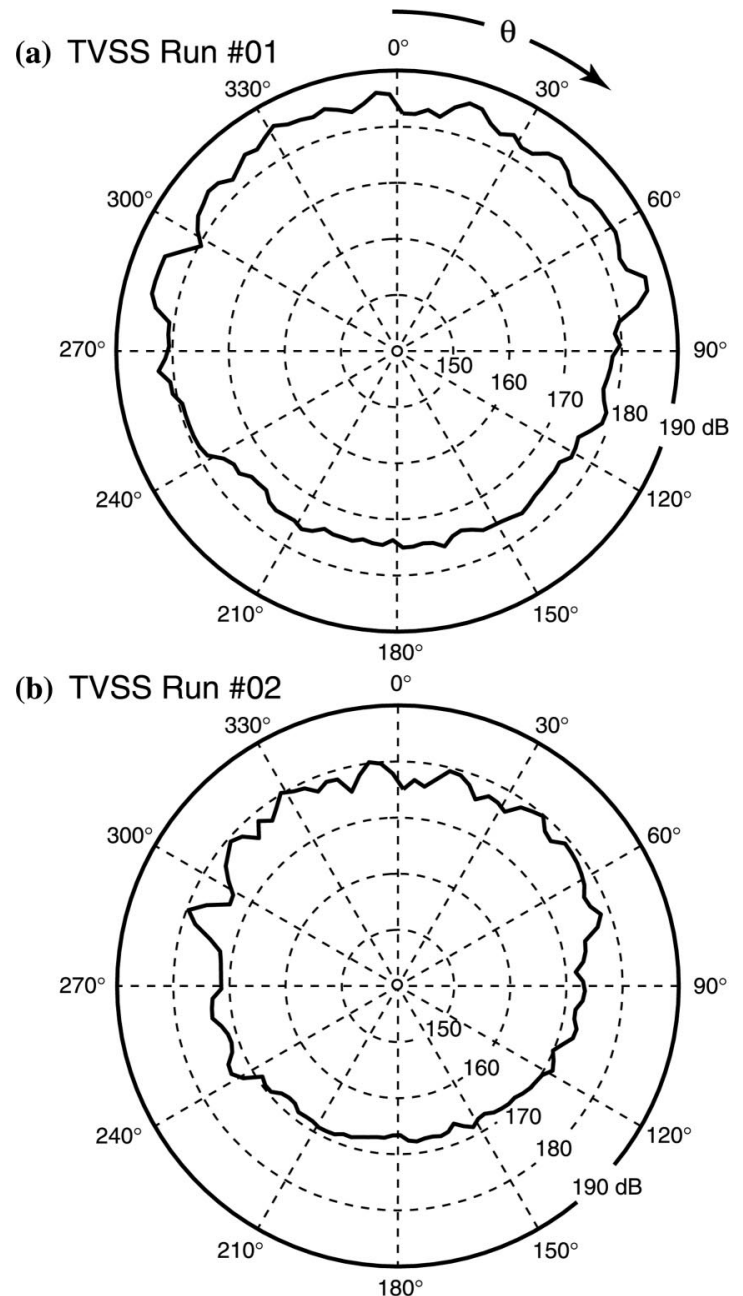

(c) TVSS Run \#03



FIG. 11. $N_{p}$-ping average of volume reverberation levels $(\overline{\operatorname{RL}}(\theta))(\mathrm{dB})$ for runs $1-3[(\mathrm{a})-(\mathrm{c})] . \theta=0$ and 180 degrees are respectively the towfish's zenith and nadir, facing the towfish's direction of travel.

\section{Environmental sources of uncertainty}

The most significant environmental source of uncertainty was the boundary echo sidelobe interference illustrated in Figs. 3 and 4. The scattering layer data (Table II) were not affected because we limited the slant range coverage of Fig. 8 to distances shorter than the first echo from the towship's wake. Although the fish school $S_{V}$ and TS data (Table I) were
TABLE III. Average volume reverberation characteristics from Fig. 11, and computed over $N_{p}$ pings. $\overline{\mathrm{RL}}_{\max }$ is the maximum over all angles $\theta$ at $\theta_{\max }$, and $\overline{\mathrm{RL}}_{\min }$ is the minimum at $\theta_{\min }$.

\begin{tabular}{lccc}
\hline \hline & Run 1 & Run 2 & Run 3 \\
\hline$N_{p}$ & 98 & 97 & 99 \\
$\overline{\mathrm{RL}}_{\max }(\mathrm{dB})$ & 187.3 & 180.2 & 184.9 \\
$\theta_{\max }$ & $355^{\circ}$ & $352^{\circ}$ & $64^{\circ}$ \\
$\overline{\mathrm{RL}}_{\min }(\mathrm{dB})$ & 174.6 & 166.8 & 169.1 \\
$\theta_{\min }$ & $181^{\circ}$ & $157^{\circ}$ & $130^{\circ}$ \\
$\overline{\mathrm{RL}}_{\max }-\overline{\mathrm{RL}}_{\min }(\mathrm{dB})$ & 12.7 & 13.4 & 15.8 \\
\hline \hline
\end{tabular}

obtained after the wake and surface echoes, analysis of the scattering strength time series in beams directed towards the fish schools showed that the upward bias in the fish school TS and $S_{V}$ due to surface reverberation was no greater than $0.5 \mathrm{~dB}$. This was fortunate, because the fish school echoes would have been significantly biased if they were closer to the TVSS or if the TVSS were towed at a greater depth, particularly if they were received at the same time as the surface echo. This illustrates that, in any shallow water multibeam application, the extent to which the data are limited by boundary echo sidelobe interference depends on the experimental geometry. Although this problem was enhanced in our results because the TVSS operated with 360 degree ensonification in the vertical plane perpendicular to the array axis, it could be reduced if the TVSS ensonified in discrete angular sectors, each electronically scanned over several pings to cover the 360 degrees about the array's axis.

There was some uncertainty regarding the sound speed used in this study because only one CTD cast was obtained about $100 \mathrm{~m}$ north of the location for run 1 (Fig. 2), approximately $4.5 \mathrm{~h}$ prior to the acoustic data collection. Any spatial variability in the local sound speed environment would have produced distortions in the processed imagery, hence errors in the scattering layer depth and thickness estimates (Table II), and fish school shape representation (Fig. 6). To evaluate the presence and effects of variability in the local sound speed environment, we processed seafloor bathymetry and sea surface relief maps using the sound speed profile in Fig. 7(b) and constant gradient ray-tracing methods, then compared them to known environmental data. ${ }^{24,25}$ If the sound speed profile were not representative of the local sound speed environment, uncompensated ray bending would produce errors in the echo arrival angles, causing the sea surface relief maps and bathymetry to "curl" upward or downward in a symmetric manner about the track's centerline. Because the processed bathymetry was consistent with that previously obtained during bathymetric surveys performed by the Naval Oceanographic Office, and the relatively flat sea surface relief maps were consistent with the calm conditions observed during the experiment, we deemed sound speed errors negligible.

Conditions near the seafloor that may adversely affect the acoustic backscatter from near-bottom fish include seafloor relief, vegetation, and suspended sediment, but none was seen to influence our results. As shown in Fig. 5, the 
seafloor in the region was relatively flat, so acoustic shadowing was not a potential source of uncertainty. Similarly, aquatic vegetation could not have been a source of ambiguity for the fish schools in Fig. 5 because the seagrasses capable of strongly scattering sound in the northeastern GOM are limited to depths shallower than $30 \mathrm{~m} .{ }^{42}$ Finally, acoustic backscatter from suspended sediment was extremely unlikely in the TVSS data because the lifting velocities of the finegrained sediments in the TVSS experiment region are much greater than the typical bottom currents expected over the Florida shelf in the winter, ${ }^{15}$ and because the scattering strengths expected from sediments at the site would have been much less than those in Table I (cf. Ref. 39).

In both the fish and zooplankton $S_{V}$ and TS measurements, uncertainties due to multiple scattering and extinction also were deemed negligible. These effects can occur in fish schools with densities of $50 / \mathrm{m}^{3}$ and greater, ${ }^{33}$ and may occur in dense swarms of macrozooplankton. ${ }^{43}$ The maximum $S_{V}$ values in the TVSS scattering layer data (Figs. 7 and 8; Table II) were not large enough to suggest that the density of scatterers was sufficiently high to produce multiple scattering or extinction. To evaluate the effects of extinction through the fish schools, we compared the mean normal incidence bottom backscattering strength over runs 1 and 2 to the instantaneous bottom backscattering strength values below the fish schools. Values below the school were less than a standard deviation from the mean values, and comparable to theoretical predictions for the silt and sand in the region, ${ }^{24}$ demonstrating that extinction was insignificant (Table I). In a similar manner, multiple scattering was ruled out by adjusting the dynamic range in Fig. 5 and analyzing the backscatter imagery under the schools (not shown). Multiple scattering returns would be evident as a "tail" below each school and "under" the bottom (e.g., Fig. 4 in Ref. 44), but such features were not found in the images.

Scattering and attenuation from resonant microbubbles are more common sources of uncertainty near the sea surface. They can be formed by breaking waves, propeller cavitation, and even zooplankton and fish. ${ }^{5,25}$ As with boundary reverberation, they can produce upward biases in TS and $S_{V}$ estimates when they are undetected. At the TVSS's acoustic frequency of $68 \mathrm{kHz}$, resonant scattering comes from bubbles with radii equal to $48 \mu \mathrm{m}$, with a single bubble target strength of $-66 \mathrm{~dB}$. For down-looking sonars near the surface, attenuation through the bubble layer will decrease the backscattered energy. These effects were negligible in this study because we used the acoustic backscatter imagery to delineate regions where acceptable data could be taken. The vertical volume images in Fig. 7 and Ref. 25 were used to define the maximum bubble depth of the wake that we set as the maximum slant range for both the scattering layer imagery and mean volume reverberation calculations.

We also used horizontal volume imagery to distinguish near-surface bubble clouds from schooling fish. Bubble clouds were observed at 3-m depth 50-100 m to either side of the ship's track, with mean volume scattering strengths of $-35 \mathrm{~dB}$, suggesting that they might be due to dense schools of large fish. Comparison between the near-surface horizontal imagery and other acoustic observations of ship wakes showed them to be bubble clouds generated by the towship's breaking bow waves, so they were not investigated with the other fish school data.

Ambient noise was a final source of uncertainty suggested by the similarity between the vertical directionality in mean volume reverberation levels (Fig. 11) and that observed for high-frequency ambient noise. ${ }^{45}$ However, for biologic, surface, and ship-generated ambient noise sources, the contributions were insignificant. Biologic sources known to generate sound around $68 \mathrm{kHz}$ include several species of dolphin and porpoise, and snapping shrimp ${ }^{46}$ that are found in the Gulf of Mexico. However, acoustic backscatter from large scatterers like dolphin and porpoise were not observed in any of the volume and near-surface imagery, and snapping shrimp are not likely in water depths deeper than $60 \mathrm{~m}^{46}$ Because the sea state was only 1.5, surface-generated noise contributions were probably less than $30 \mathrm{~dB}$ re $1 \mu \mathrm{Pa}$. Propeller cavitation, as evidenced by the dense bubble clouds in the towship's wake (Fig. 7), would have dominated the towship-generated noise sources, but a review of cavitation noise data at frequencies near $68 \mathrm{kHz}$ for ships with characteristics similar to the TVSS towship's ${ }^{47}$ (e.g., Fig. 10.15 in Ref. 4) suggests that the cavitation noise level during the TVSS experiment would have been 90-100 dB re: $1 \mu \mathrm{Pa}$ @ $1 \mathrm{~m}$, and even less at the TVSS due to spherical spreading and absorption losses. Had the TVSS operated at a lower frequency, and closer to the towship, the cavitation noise levels may have been significant.

\section{SUMMARY AND CONCLUSIONS}

In this study, we have used the data collected by the TVSS to demonstrate the advantages and limitations of multibeam sonars in bioacoustic applications. TVSS imagery showed that the most significant limitation was boundary echo sidelobe interference, which prevented zooplankton remote sensing in the volume near the range of the first boundary echo, and fish detection near the range of the first bottom echo. The 3D representation of a near-bottom fish school demonstrated the fundamental limitation of sonar resolution inherent in both multibeam and single beam characterizations of scattering fields. Angular variation in the transmit array beampattern also contributed to uncertainties in the TVSS data.

Despite these limitations, the TVSS still provided more coverage than that possible with a single beam sonar, and we used this advantage to characterize the $3 \mathrm{D}$ acoustic structure of near-bottom schooling fish and zooplankton scattering layers in a shallow water region of the northeastern Gulf of Mexico. Supporting previous studies in the region, the TVSS scattering layer imagery indicated that the vertical distribution of zooplankton is closely associated with the mixed layer depth. The TVSS geometry also provided the unique capability to characterize the vertical angular dependence of volume reverberation, shown to be affected by bioacoustic scattering layers lying above the sonar. In the future, modifications of the transmit array beampattern or ping repetition cycle, and the application of sidelobe cancellation techniques, could reduce the effects of boundary reverberation 
and increase the potential for toroidal multibeam sonars in bioacoustic remote sensing applications.

\section{ACKNOWLEDGMENTS}

This work was funded by the Office of Naval Research under ONR-NRL Contract No. N00014-96-1-G913. The authors would like to thank CAPT Tim Schnoor, USN (ONR), Sam Tooma, and Maria Kalcic (NRL) for their support; Candy Robertson and Lisa Tubridy (CSS) for information on the TVSS; and Pat Jordan (MPL) for administrative support. Chris Gledhill (NMFS) and Jason Link (NMFS) are thanked for providing the NMFS Small Pelagics Report. ${ }^{17}$ Thanks are due to Jo Griffith (MPL) for help with the figures.

\section{APPENDIX: TWO-DIMENSIONAL VARIANCE SPECTRUM}

The two-dimensional variance spectrum in Fig. 9 is calculated from the backscattering coefficients $\left(s_{V}\right)$ corresponding to each image in Fig. 8, where $S_{V}=10 \log _{10}\left(s_{V}\right)$. The $s_{V}$ data for each image were first resampled vertically to $1.4-\mathrm{m}$ depth intervals. Because the sidescanning procedure used to form the images resulted in nonuniform sample spacing which decreases away from normal incidence, the majority of the samples have spacing smaller than $1.4 \mathrm{~m}$, so they were subsampled. A few samples near normal incidence $(z$ $=78 \mathrm{~m}$ ) are spaced $2.5 \mathrm{~m}$ apart, and were interpolated to 1.4-m spacing. The average horizontal sample spacing in each image is $4.1 \mathrm{~m}$. The resulting $M \times N$ image, denoted $s_{V}(m, n)$, is demeaned according to

$s_{V}^{\prime}(m, n)=s_{V}(m, n)-(1 / M N) \sum_{m=1}^{M} \sum_{n=1}^{N} s_{V}(m, n) \quad\left(\mathrm{m}^{-1}\right)$.

The two-dimensional discrete Fourier transform of $s_{V}^{\prime}(m, n)$ is computed as ${ }^{48}$

$$
\begin{aligned}
F_{V}(p, q)= & (1 / M N) \sum_{m=1}^{M} \sum_{n=1}^{N} s_{V}^{\prime}(m, n) \\
& \times e^{-i 2 \pi(p(m-1) / M+q(n-1) / N)},
\end{aligned}
$$

where $p$ and $q$ are vertical and horizontal spatial frequency indices, respectively. The variance spectrum is then

$$
V_{V}(p, q)=(1 / M N)\left|F_{V}(p, q)\right|^{2} \quad\left(\mathrm{~m}^{-2}\right) .
$$

Thus, the variance spectrum is simply the two-dimensional power spectrum of the demeaned image. Figure 9 is the result of averaging the six spectra corresponding to Fig. 8.

The relationship between the indices $p$ and $q$ and their corresponding spatial frequencies $\mu$ and $\nu$ is

$\nu=(1 / d z)(p-M / 2) / M, \quad \mu=(1 / d y)(q-N / 2) / N$,

where $d z$ and $d y$ are the vertical and horizontal sampling intervals, respectively. The maximum and minimum positive resolvable spatial frequencies are given by

$$
\begin{array}{ll}
\nu_{\max }=1 /(2 d z), & \mu_{\max }=1 /(2 d y), \\
\nu_{\min }=2 /(M d z), & \mu_{\min }=2(N d y) .
\end{array}
$$

If the total depth and along-track distance spanned by each image in Fig. 8 are denoted $Z$ and $Y$, then the minimum resolvable spatial frequencies are also given by

$$
\nu_{\min }=2 / Z, \quad \mu_{\min }=2 / Y \text {. }
$$

Thus, for Figs. 8 and 9, $d z=1.4 \mathrm{~m}, d y=4.1 \mathrm{~m}, Z=100 \mathrm{~m}$, and $Y=410 \mathrm{~m}$, so that

$$
\begin{array}{ll}
\nu_{\max }=0.35 \mathrm{~m}^{-1}, & \mu_{\max }=0.12 \mathrm{~m}^{-1}, \\
\nu_{\min }=0.02 \mathrm{~m}^{-1}, & \mu_{\min }=0.005 \mathrm{~m}^{-1} .
\end{array}
$$

The total sample variance in the backscattering coefficients $s_{V}(m, n)$ corresponding to each image in Fig. 8 is given by 49

$$
1 /(M N) \sum_{m=1}^{M} \sum_{n=1}^{N}\left|s_{V}^{\prime}(m, n)\right|^{2},
$$

which can be related to the variance spectrum by applying Parseval's theorem generalized for the two-dimensional Fourier transform to Eq. (A2):

$(1 / M N)^{2} \sum_{p=1}^{M} \sum_{q=1}^{N}\left|F_{V}(p, q)\right|^{2}=(1 / M N) \sum_{m=1}^{M} \sum_{n=1}^{N}\left|s_{V}^{\prime}(m, n)\right|^{2}$.

Substituting (A3) into (A9) yields

$(1 / M N) \sum_{p=1}^{M} \sum_{q=1}^{N} V_{V}(p, q)=(1 / M N) \sum_{m=1}^{M} \sum_{n=1}^{N}\left|s_{V}^{\prime}(m, n)\right|^{2}$,

which shows that the average value of the variance spectrum is equal to the total sample variance in the original data.

${ }^{1}$ T. C. Gallaudet, C. P. de Moustier, and M. Kalcic, "Imaging the ocean boundaries and volume with the Toroidal Volume Search Sonar (TVSS)," in Proceedings of the Fourth Annual Symposium on the Mine Problem, 13-16 March 2000, Monterey, CA.

${ }^{2}$ G. Rose, "Acoustics in fisheries in the 21st century," J. Acoust. Soc. Am. 108, 2457 (2000).

${ }^{3}$ C. F. Eyring, R. J. Christensen, and R. W. Raitt, "Reverberation in the sea," J. Acoust. Soc. Am. 20, 462-475 (1948)

${ }^{4}$ R. J. Urick, Principles of Underwater Sound, 3rd ed. (Peninsula, Los Altos, CA, 1983).

${ }^{5}$ H. Medwin and C. S. Clay, Fundamentals of Acoustical Oceanography (Academic, San Diego, 1998).

${ }^{6} \mathrm{~B}$. Pedersen and M. Trevorrow, "Continuous monitoring of fish in a shallow channel with a fixed horizontal sonar," J. Acoust. Soc. Am. 105, 3126-3135 (1999).

${ }^{7}$ O. A. Misund, A. Aglen, and E. Fronaes, "Mapping the shape, size, and density of fish-schools by echo-integration and a high resolution sonar," ICES J. Mar. Sci. 52, 11-20 (1995).

${ }^{8}$ T. W. Steig and S. V. Johnston, "Monitoring fish movement patterns in a reservoir using horizontally scanning split-beam techniques," ICES J. Mar. Sci. 53, 435-441 (1996).

${ }^{9}$ D. M. Farmer, M. V. Trevorrow, and B. Pedersen, "Intermediate range fish detection with a $12 \mathrm{kHz}$ sidescan sonar," J. Acoust. Soc. Am. 105, 24812490 (1999)

${ }^{10} \mathrm{P}$. Greenblatt, "Distributions of volume scattering observed with an 87.5 kHz sonar,” J. Acoust. Soc. Am. 71, 879-885 (1982).

${ }^{11}$ D. V. Holliday and R. E. Pieper, "Volume scattering strengths and zooplankton distributions at acoustic frequencies between 0.5 and $3 \mathrm{MHz}$," J. Acoust. Soc. Am. 67, 135-146 (1980)

${ }^{12}$ D. McGehee and J. S. Jaffe, "Three-dimensional swimming behavior of individual zooplankters: observations using the acoustical imaging system FishTV," ICES J. Mar. Sci. 53, 363-369 (1996).

${ }^{13}$ M. Soria, P. Freon, and F. Gerlotto, "Analysis of vessel influence on spatial behaviour of fish schools using multi-beam sonar and conse- 
quences for biomass estimates by echo-sounder," ICES J. Mar. Sci. 53, 453-458 (1996)

${ }^{14}$ O. Misund, A. Aglen, J. Hamre, E. Ona, I. Rottingen, D. Skagen, and J. Valdemarsen, "Improved mapping of schooling fish near the surface: comparison of abundance estimates obtained by sonar and echo integration,” ICES J. Mar. Sci. 53, 383-388 (1996).

${ }^{15}$ G. A. Maul, "The annual cycle of the Gulf Loop Current Part I: Observations during a one-year time series," J. Mar. Res. 35, 29-47 (1977).

${ }^{16}$ T. C. Gallaudet, "Shallow water acoustic backscatter and reverberation measurements using a $68 \mathrm{kHz}$ cylindrical array," Ph.D. dissertation, University of California, San Diego, 2001.

${ }^{17}$ J. S. Link, T. A. Henwood, and C. T. Gledhill, Small Pelagics in the Gulf of Mexico: A Description of the Abundance Geographic Distribution, Size, and Depth Distribution of Major Pelagic Species (National Marine Fisheries Service, Southeast Fisheries Science Center, Pascagoula, MS, 1997).

${ }^{18}$ T. L. Hopkins, "The vertical distribution of zooplankton in the eastern Gulf of Mexico," Deep-Sea Res., Part A 29, 1069-1083 (1982).

${ }^{19}$ R. A. Zimmerman and D. C. Biggs, "Patterns of distribution of sound scattering zooplankton in warm- and cold-core eddies in the Gulf of Mexico, from a narrowband acoustic Doppler current profiler survey," J. Geophys. Res. 104, 5251-5262 (1999).

${ }^{20}$ T. L. Hopkins, D. M. Milliken, L. M. Bell, E. J. McMichael, J. J. Heffernan, and R. V. Cano, "The landward distribution of oceanic plankton and micronekton, over the west Florida continental shelf as related to their vertical distribution," J. Plankton Res. 3, 645-658 (1981).

${ }^{21}$ P. B. Ortner, R. L. Ferguson, S. R. Piotrowicz, L. Chesal, G. Berberian, and A. V. Palumbo, "Biological consequences of hydrographic and atmospheric advection within the Gulf Loop Intrusion,"” Deep-Sea Res., Part A 31, 1101-1120 (1984).

${ }^{22}$ P. B. Ortner, L. C. Hill, and S. R. Cummings, "Zooplankton community structure and copepod species composition in the northern Gulf of Mexico," Cont. Shelf Res. 9, 387-402 (1989).

${ }^{23}$ T. C. Gallaudet and C. P. de Moustier, "On optimal amplitude shading for arrays of irregularly spaced or non-coplanar elements," IEEE J. Ocean. Eng. 25, 553-567 (2000).

${ }^{24}$ T. C. Gallaudet and C. P. de Moustier, "Using environmental information to estimate and correct for errors in bathymetry and seafloor acoustic imagery," IEEE J. Ocean Eng. submitted (2002).

${ }^{25}$ T. C. Gallaudet and C. P. de Moustier, "Sea surface and volume backscattering strength measurements in the microbubble field of a ship's wake," J. Acoust. Soc. Am. submitted (2001).

${ }^{26}$ R. W. Nero, C. H. Thompson, J. R. Dubberley, and R. H. Love, "Herring hydroglyphics in littoral waters of the northern Gulf of Mexico," J. Acoust. Soc. Am. 108, 2489 (2000).

${ }^{27}$ R. C. Herron, T. D. Leming, and J. Li, "Satellite-detected fronts and butterfish aggregations in the northeastern Gulf of Mexico," Cont. Shelf Res. 9, 569-588 (1989).

${ }^{28}$ R. Love, "Target strength of an individual fish at any aspect," J. Acoust. Soc. Am. 62, 1397-1403 (1977).

${ }^{29}$ K. G. Foote, "Fish target strengths for use in echo integrator surveys," J. Acoust. Soc. Am. 82, 981-987 (1987).

${ }^{30}$ A. J. Pluddemann and R. Pinkel, "Characterization of the patterns of diel migration using a Doppler sonar," Deep-Sea Res., Part A 36, 509-530 (1989).
${ }^{31}$ L. Lecornu, V. Burdin, C. Scalabrin, and C. Hamitouche, "Fish school analysis from multibeam sonar image processing," Proc. IEEE Oceans '98, Vol. 1, pp. 587-591 (1998).

${ }^{32}$ R. K. Johnson, "Sound scattering from a fluid sphere revisited," J. Acoust. Soc. Am. 61, 375-377 (1977).

${ }^{33}$ T. K. Stanton, R. D. Nash, R. L. Eastwood, and R. W. Nero, "A field examination of acoustical scattering from marine organisms at $70 \mathrm{kHz}$," IEEE J. Ocean. Eng. 12, 339-348 (1987).

${ }^{34}$ R. H. Love, "Dorsal-aspect target strength of an individual fish," J. Acoust. Soc. Am. 49, 816-823 (1971).

${ }^{35}$ D. L. Mackas and C. M. Boyd, "Spectral analysis of zooplankton spatial heterogeneity," Science 204, 62-64 (1979).

${ }^{36}$ R. W. Nero and J. J. Magnuson, "Characterization of patches along transects using high resolution $70 \mathrm{kHz}$ integrated acoustic data," Can. J. Fish. Aquat. Sci. 46, 2056-2064 (1989).

${ }^{37}$ P. H. Wiebe, "Small scale distribution in oceanic zooplankton," Limnol. Oceanogr. 15, 205-217 (1970).

${ }^{38}$ C. F. Greenlaw and W. G. Pearcy, "Acoustical patchiness of mesopelagic micronekton," J. Mar. Res. 43, 163-178 (1985).

${ }^{39}$ P. H. Wiebe, T. K. Stanton, M. C. Benfield, D. G. Mountain, and C. H. Greene, "High-frequency acoustic volume backscattering in the Georges Bank coastal region and its interpretation using scattering models," IEEE J. Ocean. Eng. 22, 445-464 (1997).

${ }^{40}$ C. H. Greene, P. H. Wiebe, C. Pelkie, M. C. Benfield, and J. M. Popp, "Three-dimensional acoustic visualization of zooplankton patchiness," Deep-Sea Res., Part II 45, 1201-1217 (1998).

${ }^{41}$ P. A. Crowther and A. Hansla, "The lifetimes, velocities, and probable origin of sonic and ultrasonic noise sources on the sea surface," in Natural and Physical Sources of Underwater Sound, edited by B. R. Kerman (Kluwer, Boston, 1993), pp. 379-392.

${ }^{42}$ S. Z. El-Sayed, W. M. Sackett, L. M. Jeffrey, A. D. Fredricks, R. P. Saunders, P. S. Conger, G. A. Fryxell, K. A. Steidinger, and S. A. Earle, "Chemistry, primary productivity, and benthic algae of the Gulf of Mexico," in Serial Atlas of the Marine Environment Folio 22 (American Geographical Society, New York, 1972).

${ }^{43}$ K. G. Foote, "Correcting acoustic measurements of scatterer density for extinction," J. Acoust. Soc. Am. 88, 1543-1546 (1990).

${ }^{44}$ T. K. Stanton, "Effects of second-order scattering on high resolution sonars," J. Acoust. Soc. Am. 76, 861-866 (1984).

${ }^{45}$ P. A. Crowther, H. J. S. Griffiths, and A. Hansla, "Dependence of sea surface noise in narrow beams on windspeed and vertical angle," in Natural and Physical Sources of Underwater Sound, edited by B. R. Kerman (Kluwer, Boston, 1993), pp. 31-44.

${ }^{46}$ Applied Physics Laboratory, APL-UW High Frequency Ocean Environmental Acoustic Models Handbook, Technical Report APL-UW TR 9407 (Univ. of Washington, Seattle, 1994), Part III.

${ }^{47}$ F. R. Young, Cavitation (McGraw Hill, 1989).

${ }^{48}$ R. N. Bracewell, The Fourier Transform and Its Applications, 2nd ed. (McGraw Hill, New York, 1986).

${ }^{49}$ J. S. Bendat and A. G. Piersol, Random Data: Analysis and Measurement Procedures, 2nd ed. (Wiley, New York, 1986). 